${ }^{1}$ Department of Cell and Developmental Biology, School of Medicine, University of Colorado Anschutz Medical Campus, Aurora, Colorado, United States of America

Hong Tan ${ }^{1, \# a, ~ R u t h ~ E . ~ F u l t o n ~}{ }^{1}$, Wen-Hai Chou²,\#b, Denise A. Birkholz, Meridee P. Mannino ${ }^{1}$, David M. Yamaguchi ${ }^{1}$, Steven G. Britt ${ }^{3, *}$

\title{
Drosophila R8 photoreceptor cell subtype specification requires Notch and hibris.
}

\author{
${ }^{2}$ Department of Molecular Medicine, University of Texas Health Science Center, \\ San Antonio, Texas, United States of America \\ ${ }^{3}$ Department of Neurology, Department of Ophthalmology, Dell Medical School, \\ University of Texas at Austin, Austin, Texas, United States of America \\ \#aCurrent Address: Department of Pathology, School of Basic Medical Sciences, \\ Xi'an Jiaotong University Health Science Center, China \\ \#b Current Address: Center for Neuropsychiatric Research, National Health \\ Research Institutes, Miaoli, Taiwan. \\ ${ }^{*}$ Corresponding Author \\ E-mail: steve.britt@austin.utexas.edu
}


Abstract

Cell differentiation and cell fate determination in sensory systems are essential for stimulus discrimination and coding of environmental stimuli. Color vision is based on the differential color sensitivity of retinal photoreceptors, however the developmental programs that control photoreceptor cell differentiation and specify color sensitivity are poorly understood. In in the compound eye is regulated by inductive signals between cells, but the exact nature of these signals and how they are propagated remains unknown. We conducted a genetic screen to identify additional regulators of this process and identified a novel mutation in the hibris gene. hibris encodes an irre cell recognition module protein (IRM). These immunoglobulin super family cell adhesion molecules include human neph and nephrin (NPHS1). hibris is expressed dynamically in the developing Drosophila melanogaster eye and loss-of-function mutations give rise to a diverse range of mutant phenotypes including disruption of the specification of R8 photoreceptors cell diversity. The specification of blue or green sensitivity in R8 cells is also dependent upon Notch signaling. We demonstrate that hibris is required within the retina, non-cell autonomously for these effects, suggesting an additional layer of complexity in the signaling process that produces paired expression of opsin genes in adjacent R7 and R8 photoreceptor cells.

\section{Author Summary}

As humans, our ability to distinguish different colors is dependent upon the presence of three different types of cone cell neurons in the retina of the eye. The cone cells express blue, green or red absorbing visual pigments that detect and discriminate between these colors. The principle of color discrimination by neurons "tuned" to different colors is an evolutionarily 
conserved specialization that occurs in many different animals. This specialization requires 1 ) visual pigments that detect different colors and 2) a developmental program that regulates the expression of these pigments in different types of cells. In this study we discovered that the fruit fly (Drosophila melanogaster) gene hibris is required for the developmental program that produces blue sensitive neurons in the fly retina. When we over-expressed hibris throughout the developing retina, extra blue sensitive cells were produced. These results demonstrate that if there is not enough hibris, too few blue sensitive cells form, but if there is too much hibris, too Introduction

Color vision in humans and most other organisms is dependent upon the expression of spectrally distinct visual pigments (opsins) in different photoreceptor cells [1-3]. The organization of photoreceptor cells within the retinal mosaic reflects a variety of different developmental mechanisms, including regional specialization, stochastic, and precise cell-cell adjacency [4]. D. melanogaster is capable of color vision and is a useful experimental system for examining the developmental programs that produce photoreceptor cells having different color sensitivities [5-12]. The compound eye consists of $~ 800$ ommatidia, each containing eight rhabdomeric photoreceptor cells ( $\mathrm{R}$ cells). The central R7 and R8 photoreceptor cells mediate polarization sensitivity and color vision $[13,14]$. As shown in Fig 1, the majority of ommatidia contain matched pairs of R7 and R8 cells expressing specific rhodopsin (Rh) visual pigments, either Rhodopsin 3 (Rh3, FBgn0003249) and Rhodopsin 5 (Rh5, FBgn0014019) (tandem magenta-blue cylinders), or Rhodopsin 4 (Rh4, FBgn0003250) and Rhodopsin 6 (Rh6, FBgn0019940) (tandem yellow-green cylinders). 

fluorescence when illuminated with blue light $[15,16]$, with pale (pR7/pR8) expressing Rh3/Rh5, while yellow (yR7/yR8) cell pairs express $R h 4 / R h 6($ Fig 1) $[10,11,17]$. This paired expression of opsin genes in adjacent R7 and R8 cells within an individual ommatidium is thought to result from a series of developmental steps. First, a subset of R7 cells stochastically and cell autonomously express spineless (ss, FBgn0003513) which represses Rh3 and induces $R$ h4 expression [18]. In pR7 cells that stochastically fail to express ss and do express Rh3, a signal is initiated that induces the expression of $R h 5$ in adjacent pR8 cells. Extensive studies have identified the genes warts (wts, FBgn0011739), melted (melt, FBgn0023001), members of the hippo (hpo, FBgn0261456) pathway, along with the TGF $\beta$ superfamily receptors baboon (babo, FBgn0011300) and thick vein (tkv, FBgn0003726), and their respective ligands as components of the inductive signal from $\mathrm{pR} 7$ that drives the expression of $R h 5$ in pR8 [12, 19-21]. In the absence of a signal from yR7, the default yR8 fate and expression of Rh6 occurs. In addition, we have found that the Epidermal growth factor receptor (Egfr, FBgn0003731) and rhomboid (rho, FBgn0004635) are also required for this process [22, 23].

Here we undertook a genetic screen to identify additional genes required for this process and show that hibris (hbs, FBgn0029082), an irre Cell Recognition Molecule (IRM) [24], NPHS1 (nephrin, Homo sapiens, HGNC:9801) related member of the Immunoglobulin Super Family (IgSF), as well as Notch (N, FBgn0004647) are required for the establishment of paired opsin expression in adjacent R7 and R8 photoreceptor cells. Interestingly, we found that hbs is required non-cell autonomously for this process, suggesting the involvement of additional interactions between R7, R8 and neighboring cells. 


\section{Results}

\section{Isolation and characterization of the a69 mutant.}

To identify genes required for the induction of $R h 5$ expression in R8 photoreceptors, we screened a collection of approximately 150 homozygous viable eye-expressing enhancer trap lines carrying insertions of the $P\{$ etau-lacZ\} transposon (FBtp0001352) [25]. This was based on the rationale that genes required for the induction of $R h 5$ expression would be expressed in the eye, the $P\{$ etau-lacZ $\}$ transposon has been especially useful in studies of the nervous system, and insertion of this element into loci of interest would provide a convenient means to identify the affected genes [25]. The percentage of $R$ h5-expressing R8 cells was determined by labeling dissociated ommatidia with antibodies against $R h 5$ and $R h 6$. Several mutants with abnormal percentages of Rh5-expressing R8 cells were noted and a69 (FBgn0026612), with the lowest percentage of $R h 5(9 \%)$ was further characterized. Immunostaining of both dissociated ommatidia and tissue sections showed that in the a69 enhancer-trap line, Rh5expressing R8 cells are reduced and most $\mathrm{R} 8$ cells have assumed the default fate and express Rh6 (Fig 2A-E, Table 1). Since mutants lacking R7 cells or having a reduced number of Rh3 expressing $\mathrm{R} 7$ cells would also show diminished $R h 5$ expression, we examined the expression of the opsins expressed in the R7 cells and found that the percentage of $R h 3$ expressing R7 cells was similar to white $^{1118}$ ( $w^{1118}, \mathrm{RRID}:$ BDSC_3605) control flies (41.9\%, Table 1). expressing R8 cells (Fig 2C,F, Table 1) compared to cinnabar ${ }^{1}$ brown ${ }^{1}$ controls $\left(c n^{1} b w^{1}\right.$, RRID:BDSC_264) consistent with the idea that the a69 enhancer trap line carries a mutation in a gene required for the induction of $R h 5$ expression in $\mathrm{R} 8$ cells. 
Table 1. Opsin Expression in Different Genetic Backgrounds.

\begin{tabular}{|c|c|c|c|c|}
\hline Genotype & $\begin{array}{c}\text { R8 cells expressing Rh5 } \\
\%(n)\end{array}$ & $\begin{array}{c}\text { R7 cells expressing Rh3 } \\
\%(n)\end{array}$ & $\begin{array}{c}\text { Mis-pairing } \\
\%(n)\end{array}$ & Figure \\
\hline$W^{1118}$ & $29(214)$ & 47 (362) & Rh4/Rh5 0 (424) & $2 A, B, C$ \\
\hline a69 & $\begin{array}{c}9(335) \\
\text { SDF } w^{1118}, p=1.9 \times 10^{-9}\end{array}$ & $42(241)$ & $\begin{array}{c}R h 3 / R h 625(253) \\
\text { SDF } c n^{1} b w^{1}, p=1.2 \times 10^{-8} \\
R h 4 / R h 50(315)\end{array}$ & $2 \mathrm{D}, \mathrm{E}, \mathrm{F}$ \\
\hline$c n^{1} b w^{1}$ & ND & ND & Rh3/Rh6 6 (240) & \\
\hline
\end{tabular}

Statistical comparisons of strains were carried out as described in the Methods; $n=$ the number of ommatidia counted. Unless indicated, the observed percentages were not significantly different from $w^{1118}$. Strains compared to another control are indicated. Abbreviations are as follows: Significantly Different From (SDF) the strain indicated, at the $p$ value shown by a two tailed test; Not Determined (ND); Not Applicable (NA). insertion in a69 was determined and found to map to the right arm of the second chromosome at position 60E (data not shown). To determine whether the P-element in a69 is the cause of the phenotype, P-element excision lines were generated and analyzed. Thirty-five homozygous strains of these excision chromosomes were analyzed by staining dissociated ommatidia with antibodies against $R h 5$ and $R h 6$, and all of them (100\%) were found to have a low $R h 5$ percentage, similar to that of a69 (data not shown). Only $1 \%$ of excision strains would be expected to retain the mutant phenotype as a result of imprecise excision, thus our inability to revert the mutant phenotype is consistent with the a69 P-element not being responsible for the mutation [26]. Furthermore, mapping via recombination analysis revealed that the a69 mutation is localized to the interval between the purple (pr, FBgn0003141) and curved (c, FBgn0000245) genes in the middle the second chromosome (Fig 3, S 1 Table), far away from the P-element insertion site in a69. From this we conclude that the a69 mutation is not associated with the insertion of the P-element. Thirty-three deficiency lines located in the region between pr and $c$ were tested for a69 complementation (Fig 4, $\mathbf{S} 2$ Table). These 
analyses narrowed the location of the a69 mutation to 51C3-51D1 (Fig 4). The lower portion of

Fig 4 shows a diagram of this genomic region, spanning $~ 300 \mathrm{~Kb}$ and encompassing 25 known protein coding genes.

To identify the gene specifically in the a69 mutation, we took two approaches. First, a subset of genes were examined for alterations in expression in the a69 mutant, and second, a large series of complementation studies were performed with alleles of known mutants in the region. cDNAs from 5 genes in the region were obtained and in-situ hybridization of third instar larval eye imaginal discs was performed on $c n^{1} b w^{1}$ (wild-type) and a69 mutants. In each case the expression pattern of the gene was not substantially disrupted in a69 mutants, suggesting that the phenotype is not due to the disruption of patterned mRNA expression of these genes in the 3rd instar eye-antennal disc. (Fig 5). hibris (hbs) was expressed strongly in the morphogenetic furrow and maintained weakly posteriorly, consistent with a previous report [27]. It was also expressed in the ocellar region and in the developing antenna. parcas (pcs, FBgn0033988) was expressed strongly in the morphogenetic furrow and in the antenna. CG10265 (FBgn0033990) did not appear to be expressed in either the eye or antennal regions. CG7639 (FBgn0033989) appeared to be weakly expressed in the region anterior to the morphogenetic furrow. caskin (ckn, FBgn0033987) was expressed anterior to the furrow and in the antenna.

We characterized $R h 5$ and $R h 6$ expression in animals heterozygous for a69 and alleles of Additional sex combs (Asx, FBgn0261823), atypical protein kinase C (aPKC, FBgn0261854), bocce (boc, FBgn0011203), charlatan (chn, FBgn0015371), Enhancer of GMR-sina 2-1 (ES2-1, FBgn0024358), Hexokinase C (Hex-C, FBgn0001187), knot (kn, FBgn0001319), Regulatory particle non-ATPase 6 (Rpn6, FBgn0028689), safranin (sf, FBgn0003367), Protein 1 of cleavage and polyadenylation factor 1 (Pcf11, FBgn0264962), scab (scb, FBgn0003326), and transposon insertions $\mathrm{P}\left\{\mathrm{A}_{26} \mathrm{O}_{9}\right\} 1$ (FBti0001751) and P\{lacW\}B6-2-25 (FBti0005748). All of these mutations complemented a69 (data not shown). 

$h b s^{1130}$ (obtained from M. Baylies) and $h b s^{2593}$ (FBal0130218). With one exception, all of these alleles fail to complement a69, Table 2. Furthermore, $h b s^{361}$ homozygotes and heteroallelic combinations of these alleles all show a substantial decrease in the proportion of $R h 5$ expression in R8 photoreceptor cells. With four exceptions, viable combinations of these alleles over deficiencies in the region show the same complementation pattern as the a69 mutant, S3 Table.

Table 2. Complementation crosses of a69, hbs alleles and $c n$ bw control.

\begin{tabular}{|c|c|c|c|c|c|}
\hline Genotype of Strains Crossed & $h b s^{361}$ & $h b s^{459}$ & $h b s^{1130}$ & $h b s^{2593}$ & $c n^{1} b w^{1}$ \\
\hline a69 & $5.0 \%(337)$ & $\begin{array}{l}22.9 \%(1164) \\
p=1.7 \times 10^{-4}\end{array}$ & $10.4 \%(201)$ & $1.5 \%(455)$ & $\begin{array}{l}25.7 \%(152) \\
p=6.4 \times 10^{-4}\end{array}$ \\
\hline$h b s^{361}$ & $16.6 \%(404)$ & $3.3 \%(456)$ & $1.4 \%(358)$ & $2.7 \%(414)$ & $\begin{array}{l}29.1 \%(320) \\
p=1.4 \times 10^{-6}\end{array}$ \\
\hline$h b s^{459}$ & & & $3.9 \%(799)$ & $2.5 \%(651)$ & $\begin{array}{c}33.3 \%(699) \\
p=1.3 \times 10^{-10}\end{array}$ \\
\hline$h b s^{1130}$ & & & & $1.2 \%(326)$ & $\begin{array}{l}26.8 \%(503) \\
p=5.2 \times 10^{-6}\end{array}$ \\
\hline$h b s^{2593}$ & & & & & $\begin{array}{l}30.7 \%(703) \\
p=8.5 \times 10^{-9}\end{array}$ \\
\hline
\end{tabular}

Statistical comparisons of strains were carried out as described in the Methods. Values shown are percentage of

181 R8 cells expressing Rh5 (number of ommatidia counted). The crossed alleles fail to complement a69 and each

182 other (shaded gray). Complementation in this table (unshaded) is an $R h 5 \%$ significantly greater than a69 183 homozygotes $(12.7 \%(267))$ by a one tailed test at the $p$ value shown. mutant that were absent in phenotypically wild type control strains (data not shown). Nonetheless, given that the gene spans over $30 \mathrm{~Kb}$ including $24 \mathrm{~Kb}$ in the first intron, it seems likely that a mutation within a regulatory region of the gene may be responsible for the hypomorphic a69 phenotype and the complex complementation pattern found with the $h b s^{459}$ allele. Thus, we believe the complementation data is fully consistent with a69 being a $h b s$ allele, $h b s^{a 69}$. 
hibris is expressed in the developing third instar eye imaginal disc.

Consistent with previous studies [28], we find that $h b s$ is expressed in the developing third instar eye imaginal disc in preclusters of photoreceptor cells emerging from the coordinately with early senseless (sens, FBgn0002573) expression in R8 just posterior to the morphogenetic furrow and this is followed by prospero (pros, FBgn0004595) expression in R7 cells 6-8 rows posterior and cone cells. cell patterning, we examined an additional allele of $h b s$ in mosaic flies. We used the ey-FLP driver to generate homozygous mutant clones in the retina and optic lobes of animals that were heterozygous for $h b s^{1130}$. We used a cell autonomous lethal to generate large homozygous mutant clones and eliminate homozygous wildtype tissue, as described [29]. Fig 7 shows a small heterozygous clone with a single $R h 5$ expressing R8 cell in an otherwise homozygous mutant retina where $R h 3$ expressing $\mathrm{R} 7$ cells are mispaired with $R$ h 6 expressing R8 cells, demonstrating a phenotype identical to a69. To further refine the spatial requirement for $h b s$ in $\mathrm{R} 7$ and R8 photoreceptor cell differentiation and opsin gene expression we compared mutant clones of $h b s^{66}$ (FBal0239852) [30] generated using ey-FLP and ey3.5-FLP [31]. ey3.5-FLP is a modified form of ey-FLP that efficiently induces clone formation in the third instar larval eye imaginal disc, but not in the lamina or medulla. Fig 6A shows loss of $h b s$ in the retina and optic lobe leads to a dramatic decrease in $R h 5$ expression and mispairing of $R h 3$ and $R h 6$ in adjacent $R 7$ and $R 8$ cells of individual ommatidia, consistent with the results obtained with $h b s^{1130}$, Fig 5 . This is in contrast to $R h 3, R h 5$ and $R h 6$ expression in a similarly FRT recombined clone of a wild type chromosome. By comparison, retina specific clones generated with ey3.5-FLP [31] also show a loss of $R h 5$ expression and mispairing of $R h 3$ and $R h 6$. These results indicate that $h b s$ is 
217 required in the retina for normal $\mathrm{R} 7$ and $\mathrm{R} 8$ photoreceptor cell differentiation and opsin gene

218 expression.

219 Overexpression of hibris is sufficient to disrupt R7 and R8 cell differentiation.

To determine whether ectopic expression of $h b s$ is sufficient to induce the expression of Rh5 in R8 photoreceptor cells, we over-expressed hbs using the GAL4-UAS system [32] and the $P\{G A L 4-n i n a E . G M R\}$ driver (FBtp0001315). Fig 7A shows that overexpression of $h b s$ is sufficient to induce $R h 5$ expression in many, but not all R8 photoreceptor cells. This occurs without perturbation of $R h 3 / R h 4 \mathrm{R} 7$ cell subtype ratio and is accompanied by mismatched Rh4/Rh5 expressing R7/Rh8 photoreceptor cells pairs (not shown). To test whether the formation of these mismatched ommatidia could result from an inappropriate signal from $R h 4$ expressing R7 cells or a defect in the default pathway and expression of Rh6 in R8 cells, we overexpressed hbs in a sev mutant background that lacks R7 photoreceptor cells. Fig 7B shows that removal of $\mathrm{R} 7$ cells leads to a dramatic reduction but not elimination of $R h 5$ expression. These results suggest that the ability of overexpressed $h b s$ to induce $R h 5$ expression in R8 cells is primarily or partially R7 photoreceptor cell independent.

\section{hibris is required non-cell autonomously for $\mathbf{R} 7$ and $\mathbf{R} 8$ cell differentiation.}

To determine whether $h b s$ is required cell-autonomously in the $\mathrm{R} 7$ and/or $\mathrm{R} 8$ photoreceptor cells to enable normal paired expression of Rh3 and Rh5, we generated smaller $h b s^{66}$ mutant clones in a heterozygous background as previously described [22]. Cells that are either wild type or heterozygous express a myristoylated, membrane associated GFP (myr.GFP, P\{GMR-myr.GFP\}, FBtp0017435), whereas cells that are homozygous mutant for hbs do not express myr.GFP [33]. We dissociated ommatidia from animals constructed in this manner and counted the expression of $R h 5$ versus $R h 6$ in ommatidia that expressed $R h 3$ in the $R 7$ cell and in which the genotype of the R7 and R8 cells could be scored. Fig 8A shows a cluster of ommatidia from the experiment labeled with antibodies against $R h 3, R h 4, R h 5, R h 6$, with myr.GFP labeling shown in Fig 8B. Mispairing of Rh3-Rh6 expression occurs in 20\% of 
$c n^{1} b w^{1}$ ommatidia that express $R h 3$ in $\mathrm{R} 7$ cells (Fig 8C), consistent with previous results [11, $22,23]$. In the mosaic analysis, there is a statistically significant increase in the percentage of mispaired $R h 3-R h 6$ expressing ommatidia ranging from 56 - 100\%, regardless of the genotype of the R7 and R8 photoreceptor cells. Particularly noteworthy is the highly abnormal and eye [34], and is known to regulate hbs during myoblast fusion [35, 36], control cell adhesion in the eye through interactions with $h b s$ [37], and $h b s$ may also play a role in $N$ cleavage [28]. To determine whether $N$ is required for the establishment of paired opsin gene expression in the R7 and R8 photoreceptor cells, we reduced $N$ activity at sequential stages of pupal development. We used shifts to a restrictive temperature of a temperature sensitive allele $N^{11 N-}$ ${ }^{t s 1}$ (FBal0012887) in an otherwise $c n^{1} b w^{1}$ background and compared with similarly treated $c n^{1}$ $b w^{1}$ controls. Fig 9A shows that at baseline without heat shock $N^{11 N-t s 1} ; c n^{1} b w^{1}$ flies have a significantly increased proportion of $R h 3: R h 4$ expressing $\mathrm{R} 7$ cells compared to $c n^{1} b w^{1}$ controls. The Rh3:Rh4 ratio is significantly increased with heat shock at $24-36$ hours after puparium formation (APF) and significantly decreased with heat shock at 36-48 hr APF compared to $N$ mutants raised at the non-restrictive temperature. Because the variation of the $R h 3: R h 4$ ratio in $\mathrm{R} 7$ cells would be expected to alter the $R h 5: R h 6$ ratio in $\mathrm{R} 8$ photoreceptors, we specifically examined the percent of $R h 3-R h 6$ mispairing as an index of impaired induction of $R h 5$ expression. We found that $R h 3-R h 6$ mispairing was significantly increased in both $N^{11 N-}$ ${ }^{t s 1} ; c n^{1} b w^{1}$ animals and $c n^{1} b w^{1}$ control animals heat shocked from 0-12 hr APF, Fig 9B. 
269 Statistically significant increases in Rh3-Rh6 mispairing were noted at 24-36 hr APF, 36-48 hr

270 APF and 48-60 hr APF in N mutant animals demonstrating a highly significant disruption in the 271 paired expression of opsin genes in R7 and R8 photoreceptor cells. Because of heat shock 272 induced lethality at 12-24 hr APF in $c n^{1} b w^{1}$ control animals, results at this time point are 273 difficult to interpret. However, these results conclusively demonstrate a requirement for $N$ 274 activity in regulating 1) $R h 3$ versus $R h 4$ expression in the $\mathrm{pR} 7$ and $\mathrm{yR}$ photoreceptors and 2) 275 coupling of $R h 3 / R h 5$ expression in adjacent $\mathrm{pR} 7$ and pR8 photoreceptor cells of the same 276 ommatidium. 


\section{Materials and Methods}

279

280

281

282

283

284

285

\section{Stocks and Genetics}

Stocks were maintained in humidified incubators on cornmeal / molasses / agar media or standard cornmeal food with malt, and transferred on a rotating basis every three weeks as described [38-40]. D. melanogaster strains were obtained from individual laboratories or the Bloomington Drosophila Stock Center (BDSC). Genotypes were constructed using conventional genetic techniques, dominant markers and appropriate balancer chromosomes $[39,41]$.

\section{Genotypes of Animals Shown in Figures}

Figure $2 \mathrm{~A}, \mathrm{~B}, \mathrm{C}: w^{1118}$

Figure 2 D, E, F: $w^{1118 ;} P\{$ etau-lacZ $\} a 69$

Figure 5, Left column: WT $=c n^{1} b w^{1}$, Right column: $w^{1118} ; P\{$ etau-lacZ $\} a 69$

Figure 6: $c n^{1} b w^{1}$

Figure 7: $y^{d 2} w^{1118} P\left\{r y^{+t 7.2}=e y-F L P . N\right\} 2 / w^{1118} ; P\left\{w^{+m W . h s}=F R T\left(w^{h s}\right)\right\} G 13 L^{*} /$ $P\left\{w^{+m W \cdot h s}=F R T\left(w^{h s}\right)\right\} G 13 h b s^{1130}$

Figure 8A: $w^{1118} / y^{d 2} w^{1118} P\left\{r y^{+t 7.2}=e y-F L P . N\right\} 2$ P\{GMR-lacZ.C(38.1)\}TPN1; $P\left\{r y^{+t 7.2}=n e o F R T\right\} 42 D h b s^{66} / P\left\{r y^{+t 7.2}=n e o F R T\right\} 42 D P\left\{w^{+t^{*}} r y^{+t^{*}}=\right.$ white-un1 $\} 47 A I(2) c l-R 11^{1}$

Figure 8B: $w^{1118} / y^{d 2} w^{1118} P\left\{r y^{+t 7.2}=e y-F L P . N\right\} 2$ P\{GMR-lacZ.C(38.1)\}TPN1; $P\left\{r y^{+t 7.2}=\right.$ neoFRT $\} 42 D P\left\{w^{+t^{*}} r y^{+t^{*}}=\right.$ white-un 1$\} 47 A / P\left\{r y^{+t 7.2}=\right.$ neoFRT $\} 42 D P\left\{w^{+t^{*}} r y^{+t^{*}}=\right.$ whiteun1\}47A I(2)Cl-R111

Figure 8C: $w^{1118} / P\left\{w^{+m C}=e y 3.5-F L P . B\right\} 1, y^{1} w^{*} ; P\left\{r y^{+t 7.2}=n e o F R T\right\} 42 D h b s^{66} /$ $P\left\{r y^{+t 7.2}=n e o F R T\right\} 42 D P\left\{w^{+t^{*}} r y^{+t^{*}}=\right.$ white-un1 $\} 47 A$ I(2)cl-R11

Figure 8D: $w^{1118} / P\left\{w^{+m C}=e y 3.5-F L P . B\right\} 1, y^{1} w^{*} ; P\left\{r y^{+t 7.2}=n e o F R T\right\} 42 D P\left\{w^{+t^{*}}\right.$ $r y^{+t^{*}}=$ white-un 1$\} 47 A / P\left\{r y^{+t 7.2}=\right.$ neoFRT $\} 42 D P\left\{w^{+t^{*}} r y^{+t^{*}}=\right.$ white-un1 $\} 47 A I(2) c l-R 11^{1}$

Figure 9A: w1118; P\{GAL4-ninaE.GMR $\} 12$ / P\{UAS-hbs.A $\}$ 
Figure 9B: $w^{1118} \operatorname{sev}^{14} ; P\{G A L 4-n i n a E . G M R\} 12 / P\{U A S-h b s . A\}$

Figure 10: $w^{1118} / y^{d 2} w^{1118} P\left\{r y^{+t 7.2}=e y-F L P . N\right\} 2 P\{G M R-l a c Z . C(38.1)\} T P N 1$;

$P\left\{r y^{+t 7.2}=n e o F R T\right\} 42 D h b s^{66} / P\left\{r y^{+t 7.2}=n e o F R T\right\} 42 D P\left\{w^{+m c}=G M R-m y r . G F P\right\} 2 R$

Figure 11: $c n^{1} b w^{1}(c n b w)$ or $y^{1} N^{11 N-t s 1} g^{2} f^{1} ; c n^{1} b w^{1},(N ; c n b w)$

$10 \mu \mathrm{m}$ cryosections were prepared and treated as previously described [11]. Dissociated ommatidia were prepared from six animals. Eyes were cut from heads using 28 gauge needles in Phosphate Buffered Saline (PBS). The retina, cornea +/- lamina tissue was shredded with needles, triturated $10 \mathrm{X}$ with a $200 \mu \mathrm{L}$ pipette tip and transferred to a microscope slide to dry at RT. Subsequent treatment was the same as cryosections. Antibodies were used at the following dilutions: directly conjugated mouse monoclonal anti-Rh5 (Texas Red, 1:100, RRID: AB_2736994) and directly conjugated mouse monoclonal anti-Rh6 (FITC, 1:100 RRID:AB_2736995) [42], mouse monoclonal anti-Rh4 (clone 11E6, 1:10, RRID:AB_2315271) $[11,42]$, mouse monoclonal anti-prospero (1:10, RRID:AB_528440, [43]), guinea pig polyclonal anti-senseless (1:1000, [44]), rabbit polyclonal anti-hibris (1:400, AS-14, RRID:AB_2568633, [45]). Secondary reagents were obtained from Life Technologies Corporation (Carlsbad, CA) or Jackson ImmunoResearch Laboratories, Inc. (West Grove, PA). An additional reagent was prepared from purified (Cell Culture Company, LLC, Minneapolis, MN) mouse monoclonal antiRh3 (RRID:AB_2315270). anti-Rh3 was directly conjugated using Alexa Fluor ${ }^{\text {TM }} 647$ Protein Labeling Kit (Invitrogen, catalogue number A20173) and used at 1:100 dilution. Immunofluorescence images were acquired with an Axioskop plus/AxioCamHRc (Carl Zeiss, Inc., Thornwood, NY) or by confocal microscopy using a Zeiss Pascal LSM (Carl Zeiss, Inc.) or 


\section{Statistical Analysis}

Comparisons of the proportions (percentages) of opsin expression in different genetic backgrounds were performed with a z-score and are shown in Table 1 and Table 2 [46]. The $z$-score was calculated using the equation:

$$
z=\frac{\left[\rho_{2}-\rho_{1}\right]-\frac{1}{2}\left(1 / n_{1}+1 / n_{2}\right)}{\sqrt{\rho_{\text {avg }} q_{\text {avg }}\left(1 / n_{1}+1 / n_{2}\right)}}
$$

$p_{1}$ and $p_{2}=$ proportions of marker expression in each of the two different genotypes under comparison. $n_{1}$ and $n_{2}=$ number of ommatidia counted for each genotype. $p_{\text {avg }}=$ average proportion for both genotypes combined. $q_{\text {avg }}=1-p_{\text {avg. }}$. The significance of the difference between the two proportions was determined from the normal distribution as a oneor two-tailed test. The $95 \%$ confidence interval of a proportion was calculated using the Wilson procedure without continuity correction [47, 48] using VasarStats [49].

\section{RNA in situ hybridization}

Eye-antennal imaginal discs from third instar larvae were dissected in PBS, fixed in 50mM EGTA / 4\% formaldehyde in PBS, rinsed in methanol, and stored in ethanol at $-20^{\circ}$. Discs were treated with ethanol/xylene $(1: 1)$, rinsed with ethanol, post-fixed in $5 \%$ formaldehyde in PBS plus $0.1 \%$ Tween (PBT), washed with PBT, and digested with Proteinase $\mathrm{K}(5 \mu \mathrm{g} / \mathrm{ml})$. Tissue was post-fixed again and pre-hybridized in hybridization buffer ( $50 \%$ deionized formamide, 5 XSSC, $1 \mathrm{mg} / \mathrm{ml}$ glycogen, $100 \mu \mathrm{g} / \mathrm{ml}$ salmon sperm DNA, $0.1 \%$ Tween) at $48^{\circ} \mathrm{C}$. Discs were hybridized overnight at $55^{\circ} \mathrm{C}$ with $2 \mu$ ldigoxigenin-labeled antisense RNA probe in $100 \mu$ l hybridization buffer. Probes were prepared from cDNA clones D1 [50], GH09755 (FBcl0125531), GM02985 (FBcl014202), LD18146 (FBcl0156485), LP09461 (Fbcl0187603) of genes hbs, pcs, CG10265, CG7639 and ckn, respectively. The hybridized imaginal discs were washed extensively with hybridization buffer at $55^{\circ} \mathrm{C}$ followed by PBT 
washes at room temperature. Discs were incubated with alkaline phosphatase-conjugated antidigoxigenin antibody $\left(1: 2000\right.$, Roche Applied Science, Indianapolis, IN) overnight at $4^{\circ} \mathrm{C}$. Discs were washed with PBT and gene expression was visualized with staining solution (100mM plus/AxioCamHRc (Carl Zeiss Inc.). at $20^{\circ} \mathrm{C}$. Male offspring were collected at the white prepuparium stage $\left(P_{0}\right)$. At $0,12,24,36$ and 48-hours after puparium formation (APF), pupae were shifted to $29^{\circ} \mathrm{C}$ for 12 hours and returned to $20^{\circ} \mathrm{C}$ until eclosion or formation of pharate adults. Retinas were dissected and ommatidia were dissociated and labeled with opsin antibodies for cell counting. 30 pupae were collected in each experimental or control group. 


\section{Discussion}

Here we describe the isolation and characterization of a novel allele of the $D$. melanogaster gene hibris, an evolutionarily conserved NPHS1 (nephrin) related IgSF member [51]. We show that hibris is required for the coordinated expression of opsin genes in adjacent R7 and R8 photoreceptor cells within the compound eye. Orthologues of this gene have been identified in many species, and numerous paralogues within species play diverse roles in organ system development and function [52]. Within the context of R7 and R8 photoreceptor cell differentiation and the regulation of opsin gene expression in the retinal mosaic, the specific functional role of $h b s$ is unclear.

As noted briefly in the Introduction, the current model for the establishment of paired opsin gene expression in the $\mathrm{R} 7$ and $\mathrm{R} 8$ photoreceptors requires the type I activin receptor baboon (babo, FBgn0011300), bone morphogenetic protein type 1B receptor thickveins (tkv, FBgn0003716), transforming growth factor (TGF) beta type II receptor punt (put, FBgn0003169), many of their ligands, ligand processing convertases, and downstream effector enzymes [21]. In addition, the tumor suppressor kinase warts (wts, FBgn0011739), hippo kinase (hpo, FBgn0261456), salvador (sav, FBgn0053193), and melted (melt, FBgn0023001) a modulator of insulin/PI3K signaling [12], the hpo signaling cascade members Merlin (Mer, FBgn0086384), kibra (kibra, FBgn0262127), and the tumor suppressor lethal (2) giant larvae (I(2)gl, FBgn0002121) [19], and the transcription factors ocelliless (oc, FBgn0004102), dorsal proventriculus (dve, FBgn0020307) [53], Pvull-Pstl homology 13 (Pph13, FBgn0023489) [54] and erect wing (ewg, FBgn0005427) [55] are also required. Although not specifically tested in every case, all of these genes are thought to function cell autonomously within the R7 or R8 photoreceptor cells.

$h b s$ is required in the eye for the induction of Rh5 expression based upon our experiments making homozygous mutant clones with ey3.5-FLP (Fig 8). However, in mosaic 
animals in which the R7 or R8 cells may be mutant or heterozygous in a mixed genotype environment, we find that $h b s$ appears to have both cell autonomous and non-cell-autonomous effects. Specifically, ommatidia that carry R7 and R8 cells that are genotypically homozygous mutant are significantly more likely to show Rh3-Rh6 expression mispairing (Fig 10C, $p<10^{-15}$ ). By contrast, in mosaic animals in which both the R7 and R8 cell of an individual ommatidium are heterozygous or homozygous wildtype, there is still a substantial reduction in Rh5 expression in R8 cells and a statistically significant (Fig 10C, $p=5.2 \times 10^{-9}$ ) increase in Rh3-Rh6 expression mispairing. This reflects a classic non-cell autonomous effect.

What could that effect be? Traditionally inductive processes are thought to occur between tissues or cells in which there is an inducer and a responder. Inductive signals are also often defined as instructive or permissive [56]. In the presence of an instructive interaction (i.e. from a pR7 cell), the responder (R8) develops in a certain way (as a pR8 cell expressing Rh5). By contrast, in the absence of the instructive interaction (yR7 or R7 cells absent, e.g. seveneless (sev) mutants), the responder (R8) does not develop in a certain way (does not become pR8 expressing Rh5, but rather becomes yR8 and expresses Rh6 instead as a default fate (with some exceptions [11]). If hbs played a formal instructive role in regulating the expression of Rh5 in R8 photoreceptor cells, then we would expect that its expression throughout the retina (GMR-Gal4; UAS-hbs) would lead to expression of Rh5 in all R8 photoreceptor cells even in the absence of R7 cells (Fig 9B). While the number of R8 cells expressing Rh5 is far higher than in sev mutants alone [10,11, 22, 23], ectopic expression of hbs in this experiment is not sufficient to induce Rh5 expression in all R8 photoreceptor cells. Therefore, hbs does not play a strictly instructive role in this process.

As a potentially permissive regulator of R8 photoreceptor cell differentiation, $h b s$ may play a role in establishing the architecture of the developing eye. Perhaps loss of $h b s$ in mosaic or fully mutant animals disrupts cellular contacts that mediate signaling between R7 and R8. There is ample evidence for disruption of cone and pigment cell differentiation and eye 
414 roughening in hbs mutants $[57,58]$. Furthermore, hbs and its binding partner roughest (rst) are

415 known to have effects on axon guidance and synapse formation in the optic lobes [59-62].

416 Perhaps interactions within the lamina or medulla are responsible for some aspect of inductive

417 signaling and expression of Rh5 in pR8. Finally, perhaps the loss of Rh5 expression in the $h b s$

418 mutant eye reflects an inability to respond to the inductive signal, a loss of competence [63].

419 We previously suggested that rhomboid (rho, FBgn000463) and the Epidermal growth factor

420 receptor (Egfr, FBgn0003731) may play a role in establishing competence of the R8 cell [22].

421 In these studies, we showed that rho is required for the induction of Rh5 expression in R8

422 photoreceptor cells, but like hbs, when rho is lost in mosaic retinas but the R7 and R8 cells of

423 an individual ommatidia are wild type or heterozygous, there remains a dramatic effect on

424 induction of Rh5 expression. Furthermore, loss of Egfr was also found to reduce the induction

425 of Rh5 expression and also affect the proportion of $\mathrm{pR} 7$ and $y \mathrm{R} 7 \mathrm{cells}$. These findings suggest

426 that hbs likely plays a permissive, non-cell autonomous role in R7 and R8 differentiation.

427 Because $h b s$ is both regulated by $N$ signaling [50] and also thought to participate in $N$

428 processing following its activation [28], our finding that $N$ is also required for induction of Rh5

429 expression is not unexpected. This result is completely consistent with the previous findings

430 that sequential loss of $N$ signaling disrupted eye development and differentiation at every time

431 point [34]. Similarly, alterations in $N$ signaling also affect the proportion of $p R 7$ and yR7 cells,

432 suggesting that it as well as Egfr may regulate what is thought to be a cell-autonomous

433 stochastic developmental process. These findings raise several notes of caution regarding the

434 potential complexity of the system and the need to rigorously test the underlying hypotheses

435 upon which the current model for R7 and R8 photoreceptor cell differentiation is based.

436 Subsequent analysis of the role of $h b s$ in R7 and R8 photoreceptor cell differentiation

437 will require further identification of its specific interaction partners in this system, either in the

438 retina or optic lobes, as well as the temporal requirement for its involvement in R7 and R8 cell

439 differentiation. Ample resources are available including available mutant strains [64], RNAi 
bioRxiv preprint doi: https://doi.org/10.1101/398222; this version posted August 22,2018 . The copyright holder for this preprint (which was not certified by peer review) is the author/funder. All rights reserved. No reuse allowed without permission.

440 transgenics [65], and temporal and spatial mis-expression tools [66-70]. Despite these

441 technical resources, defining the precise role of $h b s$ in R7 and R8 differentiation will likely yield

442 a complex system, reflecting coregulation of the IRM proteins [71], involvement of large

443 complexes associated with scaffolding proteins [72], functional or genetic redundancy,

444 compensation [73] and feedback. 


\section{Acknowledgements}

447 We thank Mary Baylies, Ruben Artero, Gerry Rubin, Amy Tang, James Mohler, and Jeff

448 Sekelsky for D. melanogaster stocks, Mary Baylies for the hbs D1 cDNA clone, Karl Fischbach

449 for the rabbit anti-hbs antibody (AS-14), and Hugo Bellen for the guinea pig anti-sens antibody.

450 Stocks obtained from the Bloomington Drosophila Stock Center (NIH P40OD018537) were

451 also used in this study. We thank Natalia Toledo Melendez for technical assistance, John

452 Aldrich and Tom Jacobsen for comments on the manuscript and thoughtful discussion. 
455

456

457

458

1. Nathans J, Thomas D, Hogness DS. Molecular genetics of human color vision: the genes encoding blue, green, and red pigments. Science. 1986;232(4747):193-202. PubMed PMID: 2937147.

2. Jacobs GH. Comparative color vision. Carterette EC, Friedman MP, editors. New York: Academic Press; 1981.

3. Wikler KC, Rakic P. Distribution of photoreceptor subtypes in the retina of diurnal and nocturnal primates. J Neurosci. 1990;10(10):3390-401. PubMed PMID: 2145402.

4. Viets K, Eldred KC, Johnston RJ, Jr. Mechanisms of Photoreceptor Patterning in Vertebrates and Invertebrates. Trends Genet. 2016;32(10):638-59. doi: 10.1016/j.tig.2016.07.004. PubMed PMID: 27615122; PubMed Central PMCID: PMCPMC5035628.

5. Quinn WG, Harris WA, Benzer S. Conditioned behavior in Drosophila melanogaster. Proc Natl Acad Sci U S A. 1974;71(3):708-12.

6. Spatz HC, Emanns A, Reichert H. Associative learning of Drosophila melanogaster. Nature. 1974;248(446):359-61.

7. Tang S, Guo A. Choice behavior of Drosophila facing contradictory visual cues. Science. 2001;294(5546):1543-7.

8. Cook T, Pichaud F, Sonneville R, Papatsenko D, Desplan C. Distinction between color photoreceptor cell fates is controlled by Prospero in Drosophila. Dev Cell. 2003;4(6):853-64. PubMed PMID: 12791270.

9. Wernet MF, Labhart T, Baumann F, Mazzoni EO, Pichaud F, Desplan C. Homothorax switches function of Drosophila photoreceptors from color to polarized light sensors. Cell. 2003;115(3):267-79. PubMed PMID: 14636555.

10. Chou WH, Hall KJ, Wilson DB, Wideman CL, Townson SM, Chadwell LV, et al. Identification of a novel Drosophila opsin reveals specific patterning of the R7 and R8 photoreceptor cells. Neuron. 1996;17(6):1101-15.

11. Chou WH, Huber A, Bentrop J, Schulz S, Schwab K, Chadwell LV, et al. Patterning of the R7 and R8 photoreceptor cells of Drosophila: evidence for induced and default cell-fate specification. Development. 1999;126(4):607-16.

12. Mikeladze-Dvali T, Wernet MF, Pistillo D, Mazzoni EO, Teleman AA, Chen YW, et al. The Growth Regulators warts/lats and melted Interact in a Bistable Loop to Specify Opposite Fates in Drosophila R8 Photoreceptors. Cell. 2005;122(5):775-87. PubMed PMID: 16143107.

13. Fortini ME, Rubin GM. The optic lobe projection pattern of polarization-sensitive photoreceptor cells in Drosophila melanogaster. Cell Tissue Res. 1991;265(1):185-91.

14. Yamaguchi S, Desplan C, Heisenberg M. Contribution of photoreceptor subtypes to spectral wavelength preference in Drosophila. Proc Natl Acad Sci U S A. 2010;107(12):5634-9. Epub 2010/03/10. doi: 0809398107 [pii]10.1073/pnas.0809398107. PubMed PMID: 20212139; PubMed Central PMCID: PMC2851746.

15. Kirschfeld K, Feiler R, Franceschini N. A photostable pigment within the rhabdomeres of fly photoreceptors no. 7. J Comp Physiol. 1978;125:275-84.

16. Franceschini N, Kirschfeld K, Minke B. Fluorescence of photoreceptor cells observed in vivo. Science. 1981;213(4513):1264-7.

17. Papatsenko D, Sheng G, Desplan C. A new rhodopsin in R8 photoreceptors of Drosophila: evidence for coordinate expression with Rh3 in R7 cells. Development. 1997;124(9):1665-73.

18. Wernet MF, Mazzoni EO, Celik A, Duncan DM, Duncan I, Desplan C. Stochastic spineless expression creates the retinal mosaic for colour vision. Nature. 2006;440(7081):174-80. PubMed PMID: 16525464.

19. Jukam D, Desplan C. Binary regulation of Hippo pathway by Merlin/NF2, Kibra, Lgl, and Melted specifies and maintains postmitotic neuronal fate. Dev Cell. 2011;21(5):874-87. Epub 
2011/11/08. doi: 10.1016/j.devcel.2011.10.004. PubMed PMID: 22055343; PubMed Central PMCID: PMC3215849.

20. Jukam D, Xie B, Rister J, Terrell D, Charlton-Perkins M, Pistillo D, et al. Opposite feedbacks in the Hippo pathway for growth control and neural fate. Science. 2013;342(6155):1238016. doi: 10.1126/science.1238016. PubMed PMID: 23989952; PubMed Central PMCID: PMC3796000.

21. Wells BS, Pistillo D, Barnhart E, Desplan C. Parallel activin and BMP signaling coordinates R7/R8 photoreceptor subtype pairing in the stochastic Drosophila retina. Elife. 2017;6. doi: 10.7554/eLife.25301. PubMed PMID: 28853393.

22. Birkholz DA, Chou WH, Phistry MM, Britt SG. rhomboid mediates specification of blue- and green-sensitive R8 photoreceptor cells in Drosophila. J Neurosci. 2009a;29(9):2666-75. Epub 2009/03/06. doi: 10.1523/JNEUROSCI.5988-08.2009. PubMed PMID: 19261861; PubMed Central PMCID: PMC2679528.

23. Birkholz DA, Chou WH, Phistry MM, Britt SG. Disruption of photoreceptor cell patterning in the Drosophila Scutoid mutant. Fly (Austin). 2009b;3(4):253-62. Epub 2009/12/02. doi: 10546 [pii]. PubMed PMID: 19949290; PubMed Central PMCID: PMC2836898.

24. Fischbach KF, Linneweber GA, Andlauer TF, Hertenstein A, Bonengel B, Chaudhary K. The irre cell recognition module (IRM) proteins. J Neurogenet. 2009;23(1):48-67. Epub 2009/01/10. doi: 907468657 [pii]10.1080/01677060802471668. PubMed PMID: 19132596.

25. Callahan CA, Thomas JB. Tau-beta-galactosidase, an axon-targeted fusion protein. Proc Natl Acad Sci U S A. 1994;91(13):5972-6.

26. Hummel T, Klambt C. P-element mutagenesis. Methods Mol Biol. 2008;420:97-117. Epub 2008/07/22. doi: 10.1007/978-1-59745-583-1_6. PubMed PMID: 18641943.

27. Dworak HA, Charles MA, Pellerano LB, Sink $\bar{H}$. Characterization of Drosophila hibris, a gene related to human nephrin. Development. 2001;128(21):4265-76. PubMed PMID: 11684662.

28. Singh J, Mlodzik M. Hibris, a Drosophila Nephrin Homolog, Is Required for Presenilin-Mediated Notch and APP-like Cleavages. Dev Cell. 2012;23(1):82-96. Epub 2012/07/21. doi: 10.1016/j.devcel.2012.04.021. PubMed PMID: 22814602.

29. Newsome TP, Asling B, Dickson BJ. Analysis of Drosophila photoreceptor axon guidance in eye-specific mosaics. Development. 2000;127(4):851-60. PubMed PMID: 10648243.

30. Grillo-Hill BK, Wolff T. Dynamic cell shapes and contacts in the developing Drosophila retina are regulated by the Ig cell adhesion protein hibris. Dev Dyn. 2009;238(9):2223-34. Epub 2009/06/09. doi: 10.1002/dvdy.21981. PubMed PMID: 19504462.

31. Bazigou E, Apitz H, Johansson J, Loren CE, Hirst EM, Chen PL, et al. Anterograde Jelly belly and Alk receptor tyrosine kinase signaling mediates retinal axon targeting in Drosophila. Cell. 2007;128(5):961-75. Epub 2007/03/14. doi: S0092-8674(07)00248-6 [pii]

10.1016/j.cell.2007.02.024. PubMed PMID: 17350579.

32. Brand $\mathrm{AH}$, Perrimon N. Targeted gene expression as a means of altering cell fates and generating dominant phenotypes. Development. 1993;118(2):401-15. PubMed PMID: 8223268.

33. Chang HC, Newmyer SL, Hull MJ, Ebersold M, Schmid SL, Mellman I. Hsc70 is required for endocytosis and clathrin function in Drosophila. J Cell Biol. 2002;159(3):477-87. Epub 2002/11/13. doi: 10.1083/jcb.200205086. PubMed PMID: 12427870; PubMed Central PMCID: PMCPMC2173062.

34. Cagan RL, Ready DF. Notch is required for successive cell decisions in the developing Drosophila retina. Genes Dev. 1989;3(8):1099-112. PubMed PMID: 2792755.

35. Artero R, Furlong EE, Beckett K, Scott MP, Baylies M. Notch and Ras signaling pathway effector genes expressed in fusion competent and founder cells during Drosophila myogenesis. Development. 2003;130(25):6257-72. PubMed PMID: 14602676.

36. Gildor B, Schejter ED, Shilo BZ. Bidirectional Notch activation represses fusion competence in swarming adult Drosophila myoblasts. Development. 2012;139(21):4040-50. doi: 10.1242/dev.077495. PubMed PMID: 23048185. 
37. Bao S. Notch controls cell adhesion in the Drosophila eye. PLoS Genet. 2014;10(1):e1004087. doi: 10.1371/journal.pgen.1004087. PubMed PMID: 24415957; PubMed Central PMCID: PMC3886913.

38. Center BDS. BDSC Cornmeal Food 2017 [cited 2018 April 26]. Available from: https://bdsc.indiana.edu/information/recipes/bloomfood.html.

39. Greenspan RJ. Fly pushing : the theory and practice of Drosophila genetics. 2nd ed. Cold Spring Harbor, N.Y.: Cold Spring Harbor Laboratory Press; 2004. xiv, 191 p. p.

40. Roberts DB. Drosophila : a practical approach. 2nd ed. Oxford, [Eng.] ; New York: IRL Press at Oxford University Press; 1998. xxiv, 389 p. p.

41. Ashburner M. Drosophila. Cold Spring Harbor, N.Y.: Cold Spring Harbor Laboratory; 1989.

42. Earl JB, Britt SG. Expression of Drosophila rhodopsins during photoreceptor cell differentiation: Insights into R7 and R8 cell subtype commitment. Gene Expr Patterns. 2006;6(7):687-94. PubMed PMID: 16495161.

43. Campbell G, Goring H, Lin T, Spana E, Andersson S, Doe CQ, et al. RK2, a glial-specific homeodomain protein required for embryonic nerve cord condensation and viability in Drosophila. Development. 1994;120(10):2957-66. PubMed PMID: 7607085.

44. Nolo R, Abbott LA, Bellen HJ. Senseless, a Zn finger transcription factor, is necessary and sufficient for sensory organ development in Drosophila. Cell. 2000;102(3):349-62. Epub 2000/09/07. PubMed PMID: 10975525.

45. Linneweber GA, Winking M, Fischbach KF. The Cell Adhesion Molecules Roughest, Hibris, Kin of Irre and Sticks and Stones Are Required for Long Range Spacing of the Drosophila Wing Disc Sensory Sensilla. PLoS One. 2015;10(6):e0128490. doi: 10.1371/journal.pone.0128490. PubMed PMID: 26053791 ; PubMed Central PMCID: PMCPMC4459997.

46. Fleiss JL, Levin BA, Paik MC. Statistical methods for rates and proportions. 3rd / ed. Hoboken, N.J.: Wiley-Interscience; 2003. xxvii, 760 p.

47. Newcombe RG. Two-sided confidence intervals for the single proportion: comparison of seven methods. Stat Med. 1998;17(8):857-72. Epub 1998/05/22. PubMed PMID: 9595616.

48. Wilson EB. Probable Inference, the Law of Succession, and Statistical Inference. Journal of the American Statistical Association. 1927;22(158):209-12. doi: 10.2307/2276774.

49. Lowry R. VasarStats: Website for Statistical Computation. 2018 [cited 2018 07/31/2018]. The Confidence Interval of a Proportion.]. Available from: http://vassarstats.net/prop1.html.

50. Artero RD, Castanon I, Baylies MK. The immunoglobulin-like protein Hibris functions as a dose-dependent regulator of myoblast fusion and is differentially controlled by Ras and Notch signaling. Development. 2001;128(21):4251-64. PubMed PMID: 11684661.

51. Kestila M, Lenkkeri U, Mannikko M, Lamerdin J, McCready P, Putaala H, et al. Positionally cloned gene for a novel glomerular protein--nephrin--is mutated in congenital nephrotic syndrome. Mol Cell. 1998;1(4):575-82. PubMed PMID: 9660941.

52. Helmstadter M, Hohne M, Huber TB. A brief overview on IRM function across evolution. J Neurogenet. 2014;28(3-4):264-9. doi: 10.3109/01677063.2014.918976. PubMed PMID: 24912528.

53. Johnston RJ, Jr., Otake Y, Sood P, Vogt N, Behnia R, Vasiliauskas D, et al. Interlocked feedforward loops control cell-type-specific Rhodopsin expression in the Drosophila eye. Cell. 2011;145(6):956-68. Epub 2011/06/15. doi: 10.1016/j.cell.2011.05.003. PubMed PMID: 21663797; PubMed Central PMCID: PMC3117217.

54. Mishra M, Oke A, Lebel C, McDonald EC, Plummer Z, Cook TA, et al. Pph13 and orthodenticle define a dual regulatory pathway for photoreceptor cell morphogenesis and function. Development. 2010;137(17):2895-904. doi: 10.1242/dev.051722. PubMed PMID: 20667913; PubMed Central PMCID: PMCPMC2938920.

55. Hsiao HY, Jukam D, Johnston R, Desplan C. The neuronal transcription factor erect wing regulates specification and maintenance of Drosophila R8 photoreceptor subtypes. Dev Biol. 
2013;381(2):482-90. doi: 10.1016/j.ydbio.2013.07.001. PubMed PMID: 23850772; PubMed Central PMCID: PMC3757101.

56. Holtzer $\mathrm{H}$. Induction of chondrogenesis: A concept in terms of mechanisms. In: Fleischmajer R, Billingham RE, editors. Epithelial-Mesenchymal Interactions. Baltimore, MD: Williams \& Wilkins; 1968. p. 152-64.

57. Bao S, Cagan R. Preferential adhesion mediated by Hibris and Roughest regulates morphogenesis and patterning in the Drosophila eye. Dev Cell. 2005;8(6):925-35. PubMed PMID: 15935781.

58. Bao S, Fischbach KF, Corbin V, Cagan RL. Preferential adhesion maintains separation of ommatidia in the Drosophila eye. Dev Biol. 2010;344(2):948-56. Epub 2010/07/06. doi: S00121606(10)00833-X [pii]10.1016/j.ydbio.2010.06.013. PubMed PMID: 20599904; PubMed Central PMCID: PMC2921583.

59. Sugie A, Umetsu D, Yasugi T, Fischbach KF, Tabata T. Recognition of pre- and postsynaptic neurons via nephrin/NEPH1 homologs is a basis for the formation of the Drosophila retinotopic map. Development. 2010;137(19):3303-13. Epub 2010/08/21. doi: dev.047332 [pii]10.1242/dev.047332. PubMed PMID: 20724453.

60. Boschert U, Ramos RG, Tix S, Technau GM, Fischbach KF. Genetic and developmental analysis of irreC, a genetic function required for optic chiasm formation in Drosophila. $J$ Neurogenet. 1990;6(3):153-71. Epub 1990/04/01. PubMed PMID: 2358965.

61. Ramos RG, Igloi GL, Lichte B, Baumann U, Maier D, Schneider T, et al. The irregular chiasm C-roughest locus of Drosophila, which affects axonal projections and programmed cell death, encodes a novel immunoglobulin-like protein. Genes Dev. 1993;7(12B):2533-47. PubMed PMID: 7503814.

62. Schneider T, Reiter C, Eule E, Bader B, Lichte B, Nie Z, et al. Restricted expression of the irreC-rst protein is required for normal axonal projections of columnar visual neurons. Neuron. 1995;15(2):259-71. PubMed PMID: 7646884.

63. Waddington $\mathrm{CH}$. Organisers \& genes. Cambridge Eng.: The University Press; 1940. x p., 1 I., 160 p. incl. front., illus., diagrs. p.

64. Gramates LS, Marygold SJ, Santos GD, Urbano JM, Antonazzo G, Matthews BB, et al. FlyBase at 25: looking to the future. Nucleic Acids Res. 2017;45(D1):D663-D71. doi: 10.1093/nar/gkw1016. PubMed PMID: 27799470; PubMed Central PMCID: PMCPMC5210523.

65. Dietzl G, Chen D, Schnorrer F, Su KC, Barinova Y, Fellner M, et al. A genome-wide transgenic RNAi library for conditional gene inactivation in Drosophila. Nature. 2007;448(7150):151-6. Epub 2007/07/13. doi: nature05954 [pii]10.1038/nature05954. PubMed PMID: 17625558.

66. Brand AH, Dormand EL. The GAL4 system as a tool for unravelling the mysteries of the Drosophila nervous system. Curr Opin Neurobiol. 1995;5(5):572-8. PubMed PMID: 8580708.

67. Bello B, Resendez-Perez D, Gehring WJ. Spatial and temporal targeting of gene expression in Drosophila by means of a tetracycline-dependent transactivator system. Development. 1998;125(12):2193-202. PubMed PMID: 9584119.

68. Roman G, Endo K, Zong L, Davis RL. P[Switch], a system for spatial and temporal control of gene expression in Drosophila melanogaster. Proc Natl Acad Sci U S A. 2001;98(22):12602-7. PubMed PMID: 11675496.

69. McGuire SE, Mao Z, Davis RL. Spatiotemporal gene expression targeting with the TARGET and gene-switch systems in Drosophila. Sci STKE. 2004;2004(220):pl6. PubMed PMID: 14970377.

70. Sun J, Tower J. FLP recombinase-mediated induction of $\mathrm{Cu} / \mathrm{Zn}$-superoxide dismutase transgene expression can extend the life span of adult Drosophila melanogaster flies. Mol Cell Biol. 1999;19(1):216-28. PubMed PMID: 9858546; PubMed Central PMCID: PMCPMC83880. 
653 71. Machado MCR, Valer FB, Couto-Lima CA, Ramos RGP. Transcriptional cross-regulation of Irre Cell Recognition Module (IRM) members in the Drosophila pupal retina. Mech Dev. 2018. Epub 2018/07/22. doi: 10.1016/j.mod.2018.07.006. PubMed PMID: 30030087.

72. Ni J, Bao S, Johnson RI, Zhu B, Li J, Vadaparampil J, et al. MAGI-1 Interacts with Nephrin to Maintain Slit Diaphragm Structure through Enhanced Rap1 Activation in Podocytes. J Biol Chem. 2016;291(47):24406-17. Epub 2016/10/21. doi: 10.1074/jbc.M116.745026. PubMed PMID: 27707879; PubMed Central PMCID: PMCPMC5114397.

73. El-Brolosy MA, Stainier DYR. Genetic compensation: A phenomenon in search of mechanisms. PLoS Genet. 2017;13(7):e1006780. Epub 2017/07/14. doi: 10.1371/journal.pgen.1006780. PubMed PMID: 28704371; PubMed Central PMCID: PMCPMC5509088.

74. Bridges CB. SALIVARY CHROMOSOME MAPS: With a Key to the Banding of the Chromosomes of Drosophila Melanogaster. Journal of Heredity. 1935;26(2):60-4. doi: 667 10.1093/oxfordjournals.jhered.a104022. 
Fig 1. Diagram of photoreceptor cell organization and opsin gene expression. Two ommatidia are shown consisting of gray cylinders corresponding to the rhabdomeres of the R1-6 photoreceptor cells. These surround the central rhabdomeres of the R7 and R8 cells. opsin gene expression in the adjacent R8 cell ( $R h 5$ in blue or $R h 6$ in green) in pale and yellow ommatidia, respectively.

Fig 2. a69 mutants have a defect in Rh5 and Rh6 expression in R8 photoreceptor cells. White eyed wild type flies ( $w^{1118}$ ) express $R h 5$ and Rh6 in a proportion of approximately $1: 2$, this is shown in a longitudinal section of the retina $(A)$ as well as in dissociated ommatidia $(B)$. (C) $w^{1118}$ flies express Rh4 and Rh6 in a paired fashion. The arrowheads indicate Rh3 expressing R7 cells that do not normally pair with Rh6 expressing R8 cells. $w^{1118 ;} P\{$ etaulacZ\}a69 mutants show a disruption in Rh5 expression, with a substantial decrease in Rh5 expression shown in both section (D) and dissociated ommatidia (E) as well as prominent mispairing between Rh3 expressing R7 cells and Rh6 expressing R8 cells in the same ommatidia (arrowheads).

\section{Fig 3. Recombination mapping of a69 to the second chromosome between prand $c$.} Three multiply marked chromosomes (al ${ }^{1} d p y^{o v 1} b^{1} p r^{1} c^{1} p x^{1} s p^{1}$, al $l^{1} d p y^{o v 1} b^{1} p r^{1}$, and $b^{1} p r^{1}$ $\left.c^{1} p x^{1} s p^{1}\right)$ were recombined with the $w^{1118 ;} P\{$ etau-lacZ\}a69 mutant. After marker identification, recombinant strains were back crossed to the a69 mutant and scored for the percentage of Rh5 expression. The regions of the recombinant chromosomes assumed to be derived from the a69 parental mutant strain are indicated in gray, while the regions assumed to be derived from the multiple marked (wild-type) chromosomes are black. Sixteen recombinant strains were phenotypically wild-type and complemented a69. Four recombinant strains were intermediate and eight strains were mutant and failed to complement a69. The four 
intermediate strains and one wild type strain, al10, differed from the expected phenotypes and column) eye-antennal imaginal discs.

may have resulted from multiple recombination events or exposure of cryptic modifier loci. See S1 Table. Complementation of a69 Recombinant Strains.

Fig 4. Cytogenetic Map, Molecular Map and Deficiency Complementation of a69. The top panel shows the cytogenetic map of the 51 region of chromosome 2R [74], used with permission. Diagramed below are the deleted regions of deficiency strains tested, the corresponding molecular map and identified protein coding genes in the region. Arrows or arrowheads indicate the orientation of gene transcription and arrow or arrowhead length corresponds to gene length at the scale indicated (K, kilobase). Data obtained from Flybase version FB2018_01 [64].

Fig 5. In situ Hybridization of a69 Candidate Genes. The figures shows in situ hybridization of biotinylated reverse strand probes prepared from hibris, parcas, CG10265, CG7639, and caskin cDNA clones (rows) against wild type ( $\left.c n^{1} b w^{1}\right)$ (left column) or a69 mutant (right

Fig 6. hibris Expression in the Third Instar Larval Eye Imaginal Disc. The figure shows a confocal microscopy flattened Z-stack series of hibris (hbs) immunolabeling (A) and triple labeling of the same wild type $\left(c n^{1} b w^{1}\right)$ specimen with antibodies against $h b s$, senseless (sens) and prospero (pros) (B). The morphogenetic furrow has moved from right (posterior) to left (anterior).

\section{Fig 7. Opsin Expression in $\boldsymbol{h b s}^{1130}$ Mosaic Mutant Retina. Large FLP-FRT retinal clones} were generated in the eye and optic lobes with ey-FLP. Panel A shows a bright field microscopy image of a single heterozygous clone (red tissue marked with $w^{+}$) within an otherwise homozygous $h b s^{1130}$ mutant retina (white tissue). B and C show one R8 photoreceptor cell expressing $R h 5$ in this heterozygous clone, whereas elsewhere in the retina, only $R h 6$ is expressed in $R 8$ photoreceptor cells. Frequent mispairing of $R h 3$ expressing $R 7$ cells and Rh6 expressing R8 cells is also shown. Rh3 (blue), Rh5 (red) and Rh6 (green) 
719 expression were detected by confocal microscopy with directly labeled monoclonal antibodies

720 as described in Materials and Methods.

721 Fig 8. Opsin Expression in hbs $^{66}$ Mutant and Wildtype Control Flies. Large FLP-FRT

722 retinal clones were generated in the eye and optic lobes with ey-FLP, panels $\mathrm{A}$ and $\mathrm{B}$, or in the 723 retina alone with ey3.5-FLP. Homozygous $h b s^{66}$ mutant clones are shown in panels $\mathrm{A}$ and $\mathrm{C}$.

724 Homozygous wild-type control clones $(+)$ are shown in panels B and D. Heterozygous tissue is 725 marked with $w^{+}$and outlined in panels B, C and D. Rh3 (blue), Rh5 (red) and Rh6 (green) 726 expression were detected by confocal microscopy with directly labeled monoclonal antibodies 727 as described in Materials and Methods.

728 Fig 9. Overexpression of hibris Induces Increased $\boldsymbol{R h} 5$ Expression. Over expression of 729 UAS-hbs with the GMR-GAL4 driver leads to an increase in $R h 5$ (red) expression, panel A. 730 Removal of R7 photoreceptor cells (sevenless ${ }^{14}$ mutation) partially suppresses the effect, 731 panel B. Rh6 expression is shown in green.

732 Fig 10. Testing for an R7 and/or R8 Cell Autonomous Requirement for hibris. Clusters of 733 dissociated ommatidia from the eyes of $h b s^{66}$ flies carrying small homozygous mutant clones 734 were examined for expression of $R h 3$ (yellow), Rh4 (red), Rh5 (blue), Rh6 (magenta) panel A, 735 and myr.GFP (green, panel B). Heterozygous or homozygous wild-type tissue is labeled with a myristoylated, membrane associated GFP (myr.GFP) (green, panel B, labeled R7+ or R8+ in panel C). Homozygous mutant tissue is unlabeled for myr.GFP (labeled R7- or R8- in panel C). Asterisks in panels $A$ and $B$ indicate two ommatidia showing myr.GFP expression in R7, R8 and other (in the case of the left ommatidia in panel B) photoreceptor cells. Panel C shows the percentage of mispairing of Rh3-Rh6 expressing R7-R8 cells in individual ommatidia (Y-axis) for unrecombined cn bw control flies, and each genotype of R7/R8 photoreceptor cells (Xaxis). Asterisks $\left(^{*}\right)$ in panel $\mathrm{C}$ indicate that Rh3-Rh6 expression mispairing is significantly different statistically from the $c n$ bw control $\left(\mathrm{n}=96\right.$ ommatidia) for $\mathrm{R} 7+\mathrm{R} 8+\left(p=5.2 \times 10^{-9}, \mathrm{n}=170\right.$ ommatidia), $\mathrm{R} 7-\mathrm{R} 8+\left(p=1.6 \times 10^{-6}, \mathrm{n}=11\right), \mathrm{R} 7+\mathrm{R} 8-\left(p=5.0 \times 10^{-5}, \mathrm{n}=6\right), \mathrm{R} 7-\mathrm{R} 8-\left(p<10^{-15}, \mathrm{n}=178\right)$. 
745 Hashtag (\#) in Panel C indicates mispairing is significantly different statistically from R7+ R8+

746 for R7- R8- $\left(p<10^{-15}, n=178\right)$. Error bars indicate the $95 \%$ confidence intervals for the $747 \quad$ measured percentages.

748 Fig 11. Analysis of Notch Function in R7 and R8 Photoreceptor Cell Differentiation. $N^{11 N-}$

$749{ }^{t s} ; \mathrm{cn}^{1} \mathrm{bw}^{1}$ (shaded columns) flies were compared to $c n^{1} b w^{1}$ control (white columns) flies.

750 Panel A shows data for the percent of $R 7$ cells expressing Rh3 versus Rh4. Panel B shows

751 data for the percent of Rh3-Rh6 mispairing in adjacent R7 and R8 photoreceptor cells within

752 an individual ommatidium. Both panels $A$ and $B$ are bar graphs showing no temperature shift

753 (none, raised continuously at $20^{\circ} \mathrm{C}$ ) or a 12 hour temperature shift (temperature raised to $29^{\circ} \mathrm{C}$

754 at the indicated time in hours after puparium formation (APF) followed by return to $20^{\circ} \mathrm{C}$ ).

755 Hashtag (\#) indicates significantly different from $c n$ bw control receiving the same treatment

$756 p<0.05$. Asterisk $\left({ }^{*}\right)$ indicates significantly different from the same genotype not heat shocked

757 (none) $p<0.05$. not recovered (heat shock induced lethality was observed for $c n$ bw at this

758 temperature shift time point). Error bars indicate the $95 \%$ confidence intervals for the

759 measured percentages. Number of ommatidia counted for $c n$ bw and $N$; cn bw respectively

760 Panel A (no heat shock 259, 446; 0-12 hr heat shock 505, 411; 12-24 hr heat shock 0, 226; 24-

$76136 \mathrm{hr}$ heat shock 285,$306 ; 36-48 \mathrm{hr}$ heat shock 509,$577 ; 48-60 \mathrm{hr}$ heat shock 610,586$)$.

762 Panel B (no heat shock 96, 232; 0-12 hr heat shock 197, 234; 12-24 hr heat shock 0, 104; 24-

$76336 \mathrm{hr}$ heat shock 103,$187 ; 36-48 \mathrm{hr}$ heat shock 183,$231 ; 48-60 \mathrm{hr}$ heat shock 232,316$)$. 


\section{Supporting Information}

S1 Table. Complementation of a69 Recombinant Strains. Recombinants described in Fig 3 were crossed to $a 69$ and the number of ommatidia counted expressing Rh5 or Rh6, Total counted, and \% Rh5 are indicated in the table. Controls for comparison were homozygous a69 mutants or a69 / $w^{1118}$ heterozygotes. Each recombinant strain was compared to both controls (right two columns) and was either not significantly different (NSD) or significantly different from (SDF) the indicated control at the $p$ value stated. Statistical comparisons of strains were carried out as described in Materials and Methods. Controls are indicated at the bottom of the table. Recombinant strains having \% Rh5 values intermediate between wild type and mutant phenotypes, but statistically significantly different from both, are shaded.

S2 Table. Complementation of $a 69$ by Deficiency Strains. A panel of thirty three deficiency stains were crossed to a69 to test for complementation. The number of ommatidia counted expressing Rh5 or Rh6, Total counted, and \% Rh5 are indicated in the table. The control for comparison was homozygous a69 mutants. Compared to a69 (right column) each deficiency over a69 was either not significantly different (NSD) or significantly different from (SDF) a69 at the $p$ value stated. Statistical comparisons of strains were carried out as described in Materials and Methods. Values for the a69 mutant are indicated at the bottom of the table. Deficiency strains failing to complement a69, which are not statistically significantly different from a69, are shaded.

S3 Table. Complementation of hibris alleles by Deficiency Strains. A panel of seven deficiencies were crossed to $a 69, h b s^{361}, h b s^{459}, h b s^{1130}, h b s^{2593}$ and $c n^{1} b w^{1}$ to test for complementation of the a69 mutant phenotype. The number of ommatidia counted expressing $R h 5$ or $R h 6$, Total counted, and \% Rh5 are indicated in the table. The control for comparison was homozygous a69 mutants. The deficiencies failed to complement the tested genotype (shaded rows) or complemented the tested genotype (white rows). Complementation was 
790 defined as significantly greater $R h 5 \%$ than (SGT) a69 homozygous mutant at the $p$ value 791 shown using a one-tailed test. Statistical comparisons of strains were carried out as described 792 in Materials and Methods. Values for the a69 mutant are indicated at the bottom of the table. 793 Crosses having results that differed from expected are noted (Exceptions).

794 S4 Table. Strain Information. Includes recombination stocks, deficiencies and alleles that 795 complement a69. Stock genetics, Flybase ID and RRID are listed where available. 
Fig 1

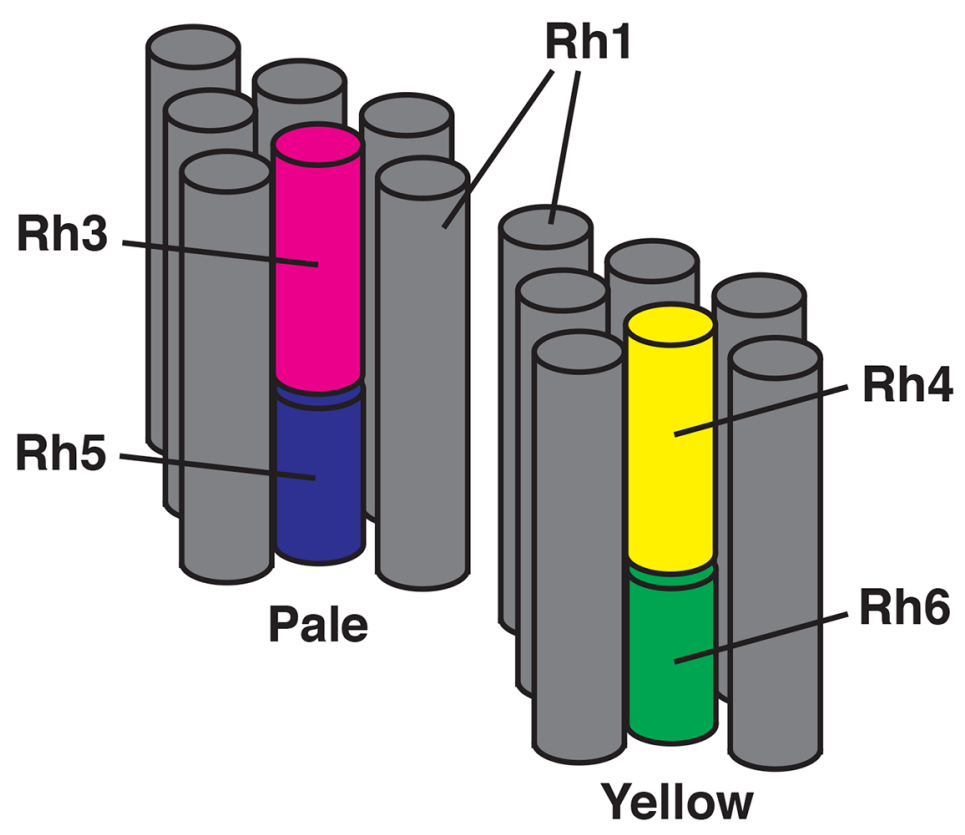


bioRxiv preprint doi: https://doi.org/10.1101/398222; this version posted August 22, 2018. The copyright holder for this preprint (which was not certified by peer review) is the author/funder. All rights reserved. No reuse allowed without permission.

Fig 2
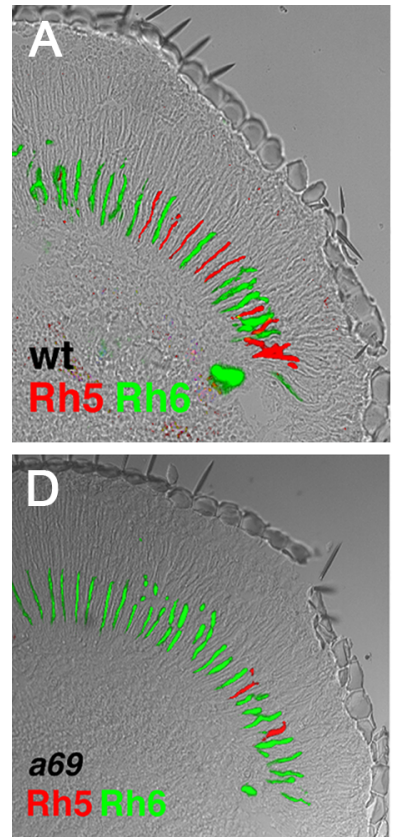
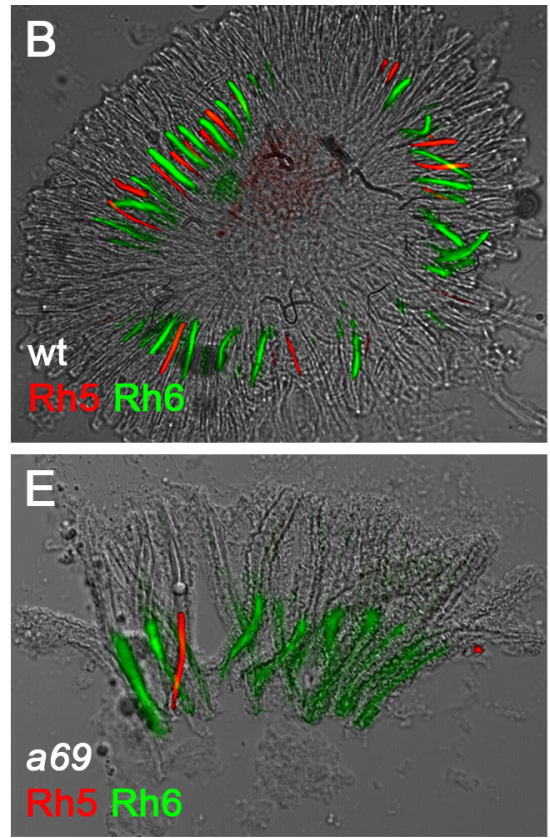
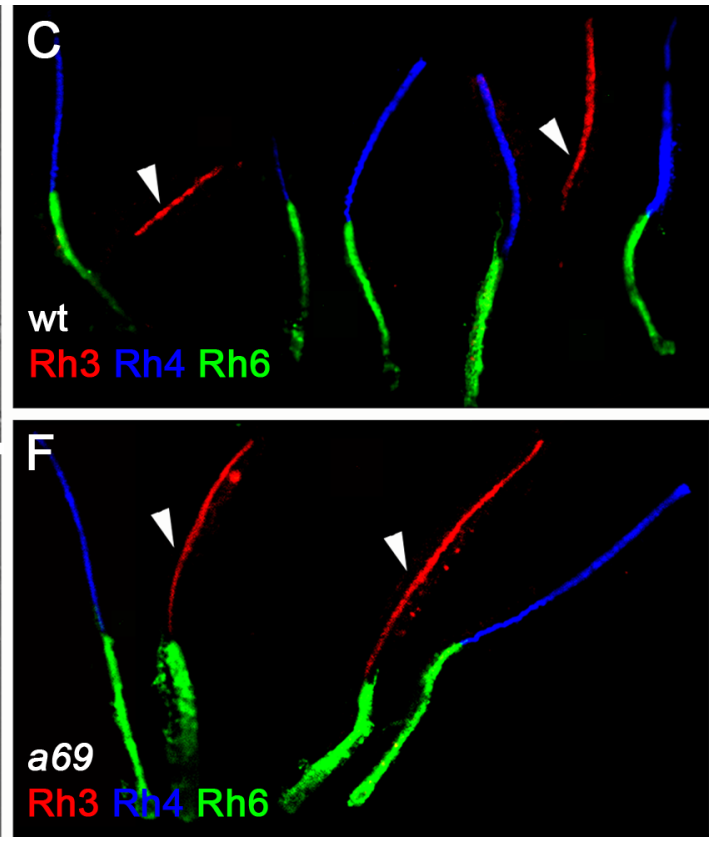
Fig 3

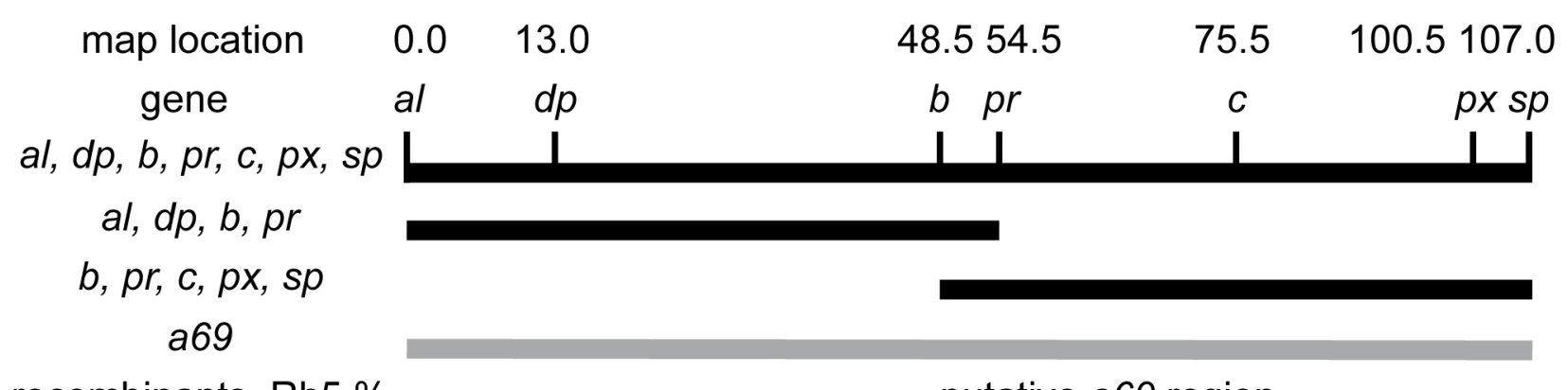

recombinants $\mathrm{Rh} 5 \%$

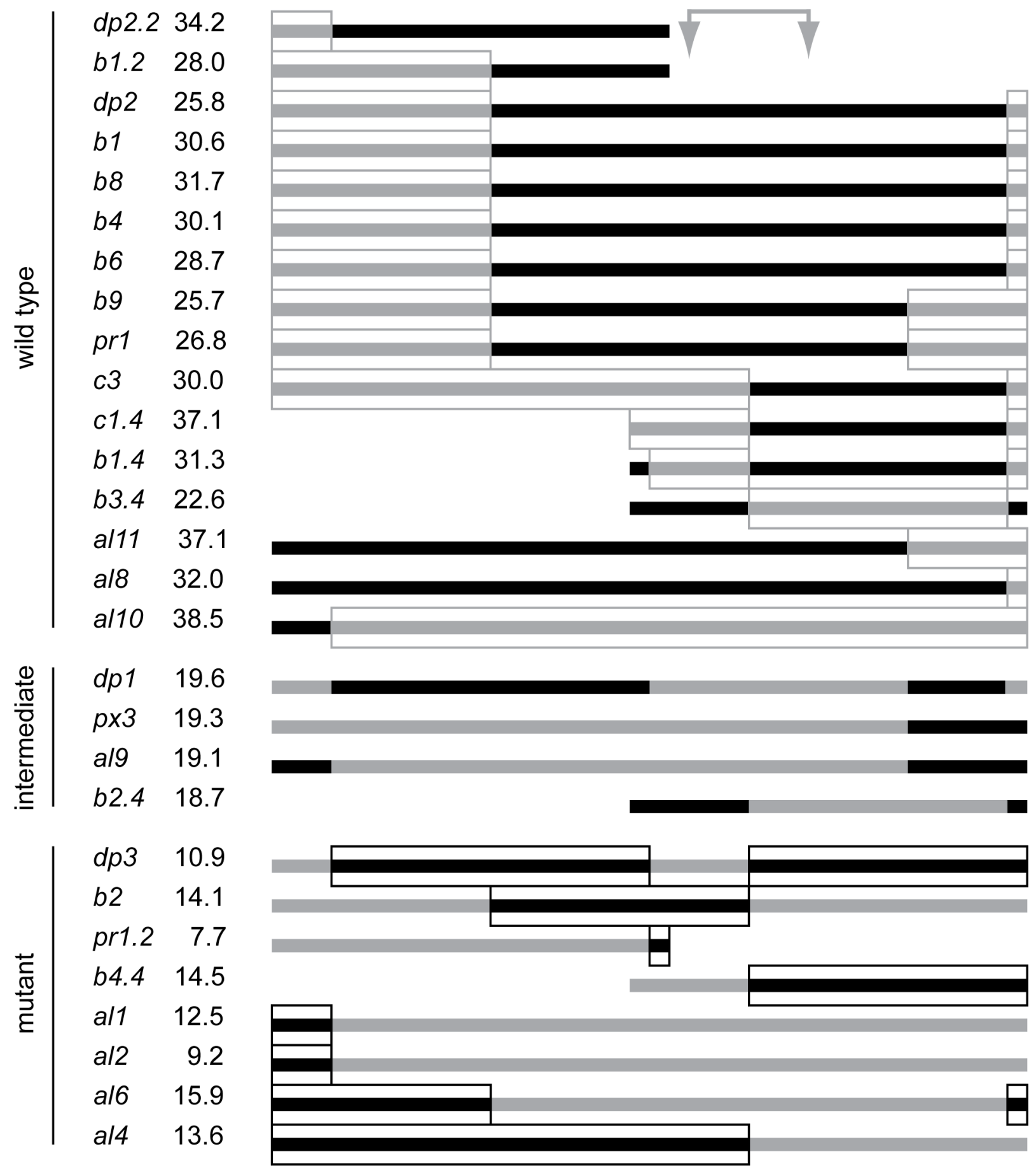



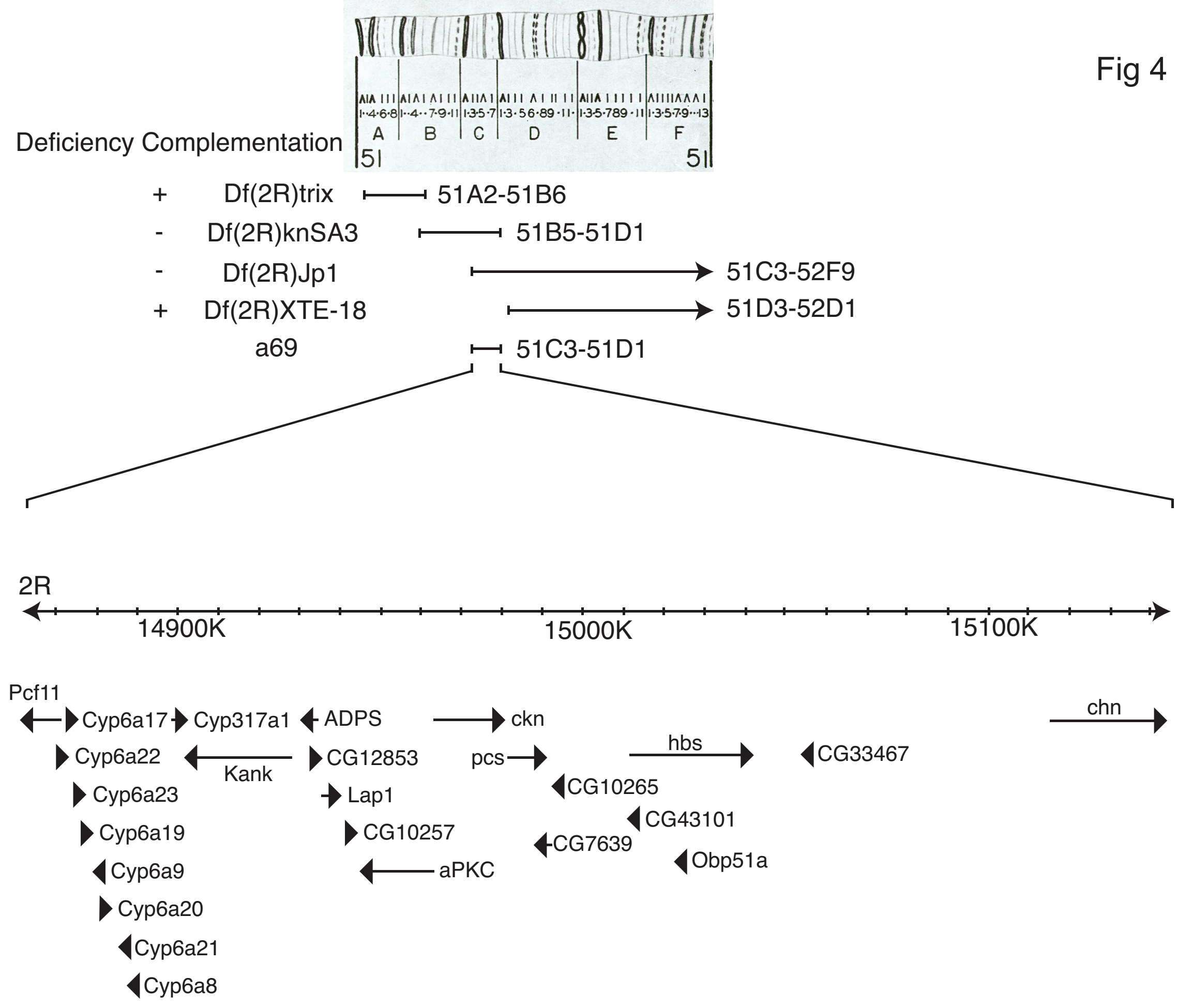
Fig 5

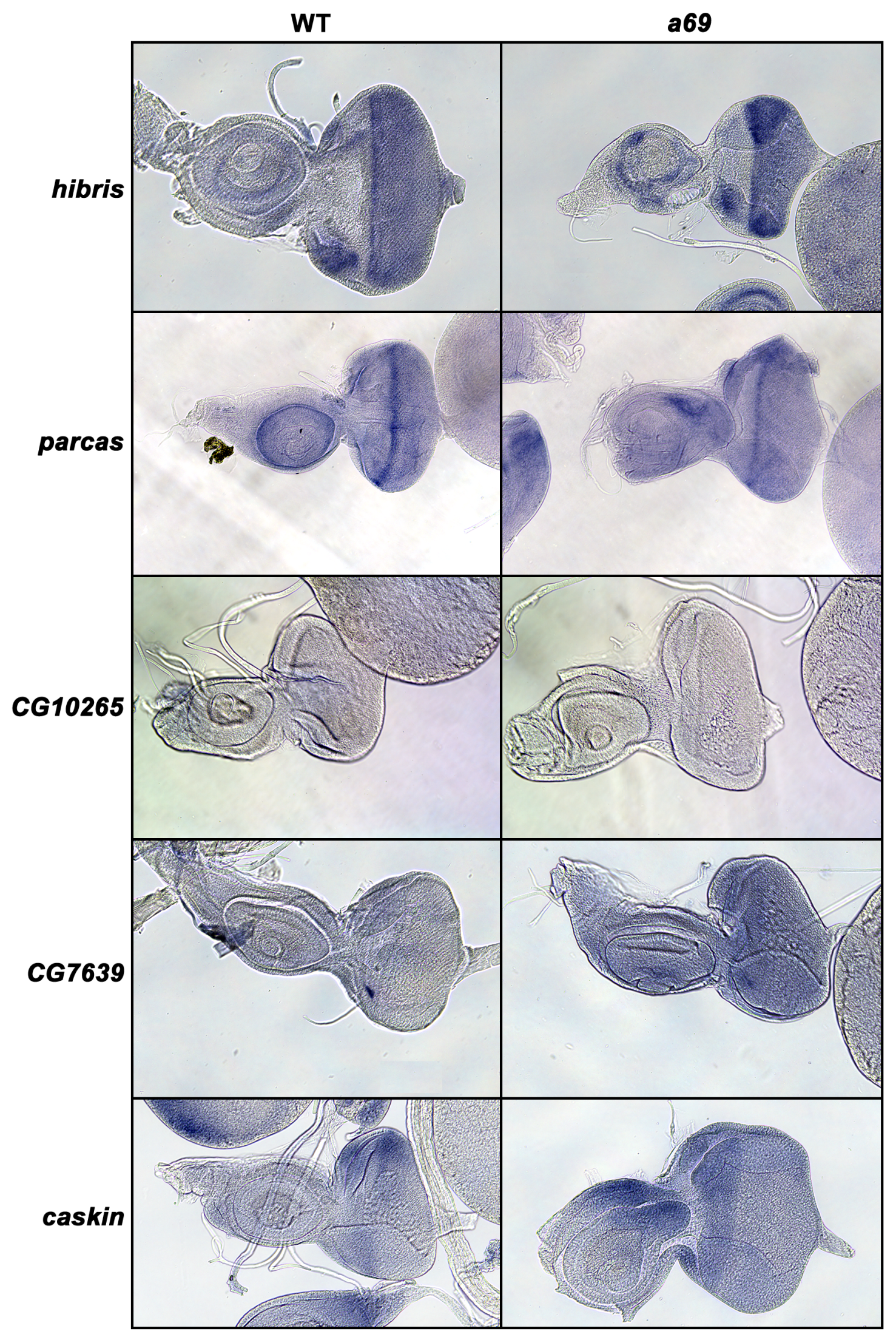


bioRxiv preprint doi: https://doi.org/10.1101/398222; this version posted August 22, 2018. The copyright holder for this preprint (which was not certified by peer review) is the author/funder. All rights reserved. No reuse allowed without permission.

\section{Fig 6}

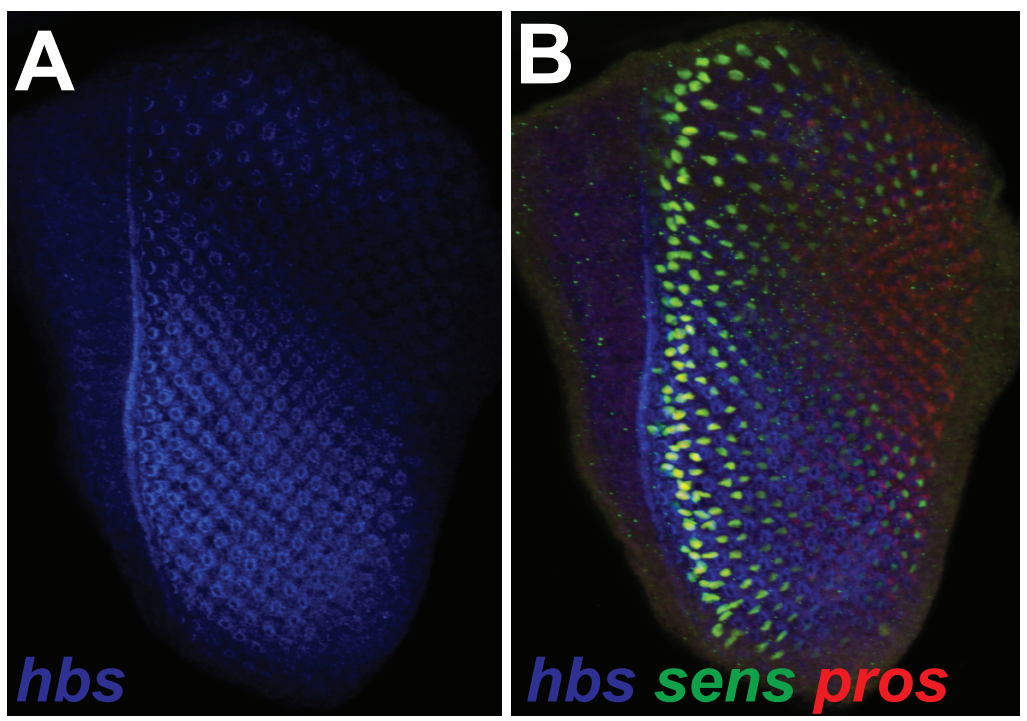


bioRxiv preprint doi: https://doi.org/10.1101/398222; this version posted August 22, 2018. The copyright holder for this preprint (which was not certified by peer review) is the author/funder. All rights reserved. No reuse allowed without permission.

Fig 7
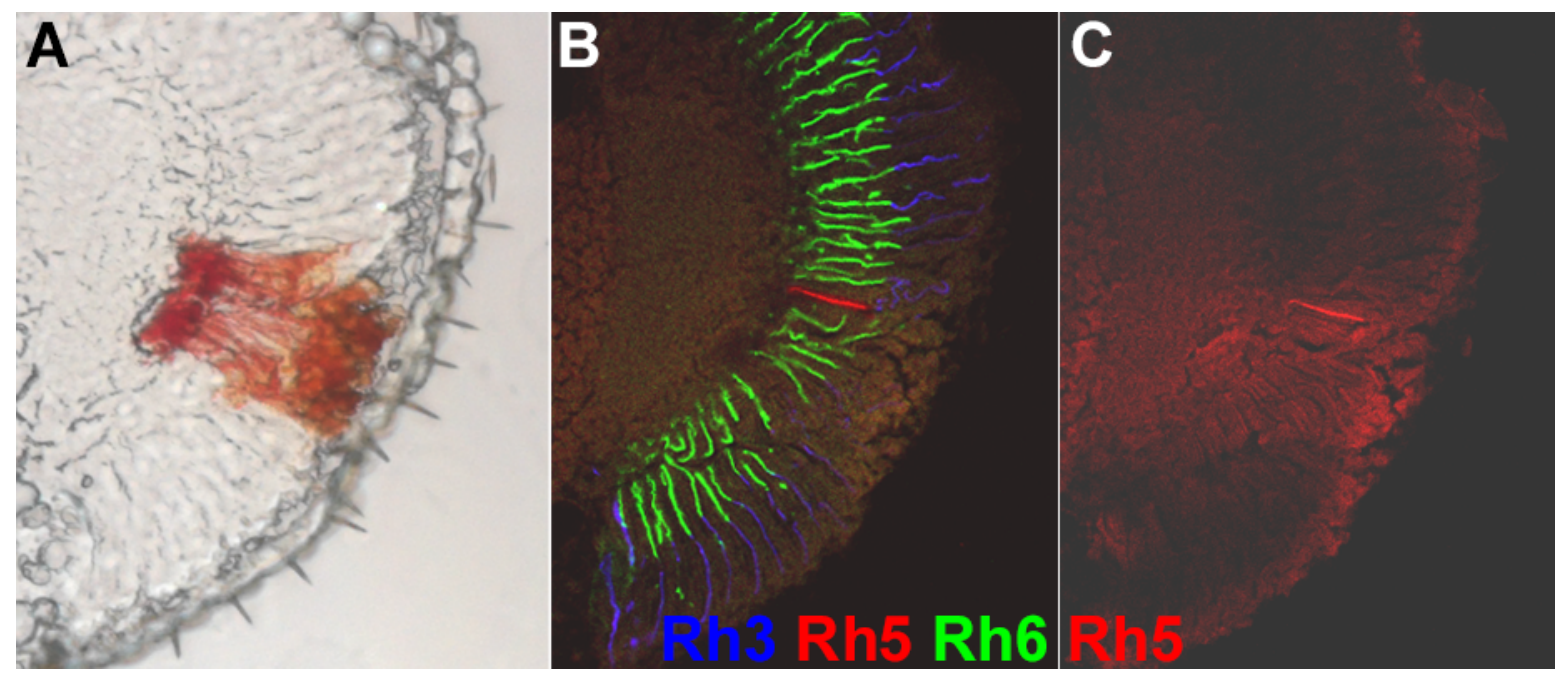


\section{Fig 8}

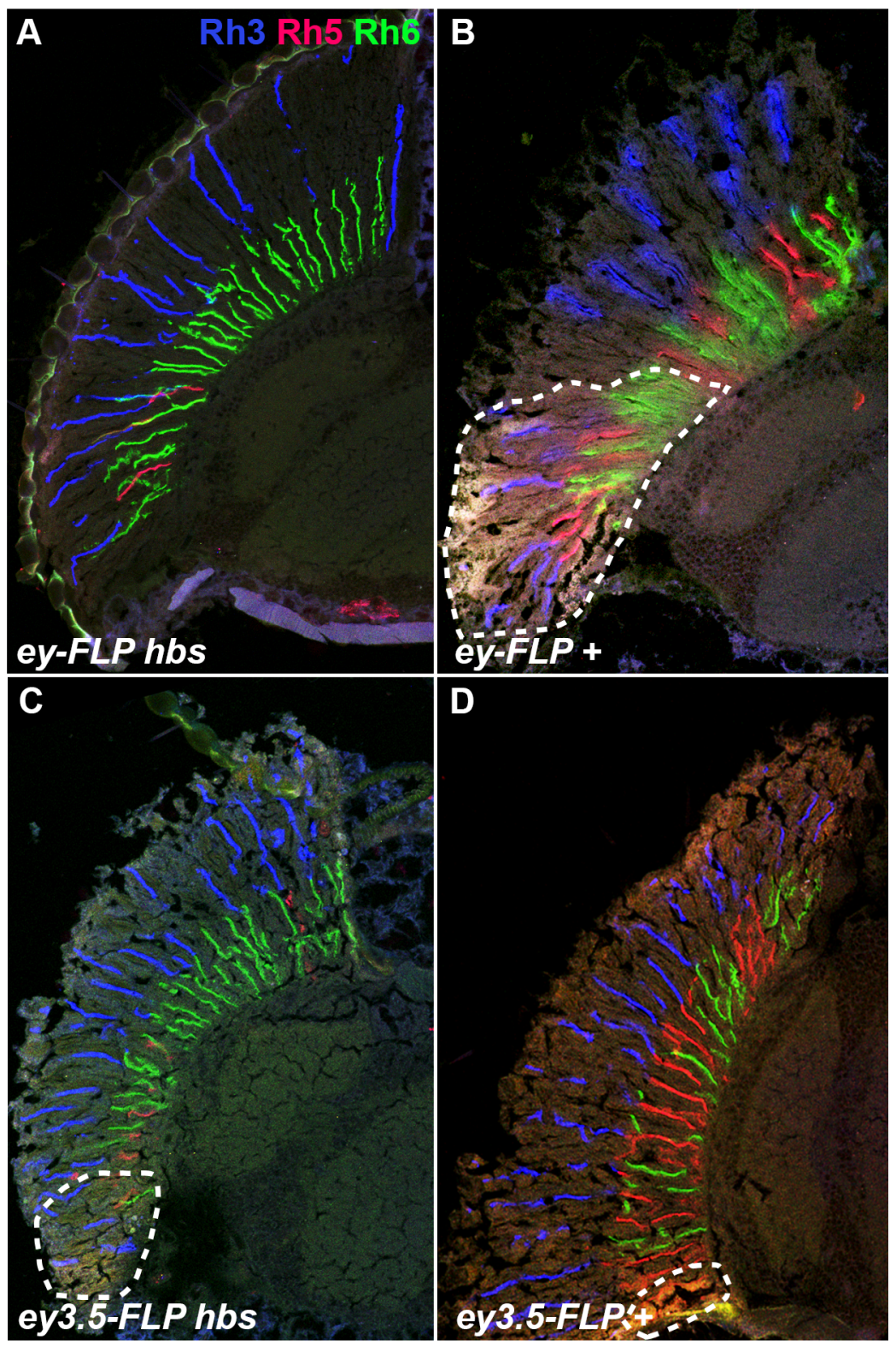


bioRxiv preprint doi: https://doi.org/10.1101/398222; this version posted August 22,2018 . The copyright holder for this preprint (which was not certified by peer review) is the author/funder. All rights reserved. No reuse allowed without permission.

\section{Fig 9}

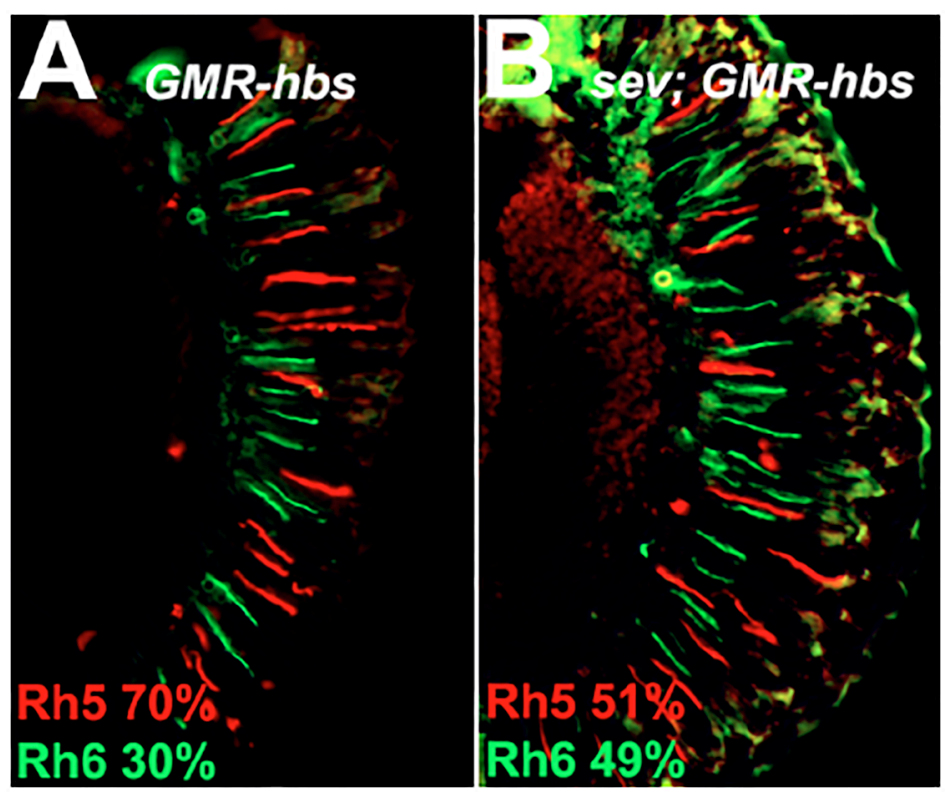


A

Rh6

Rh5
C

Fig 10

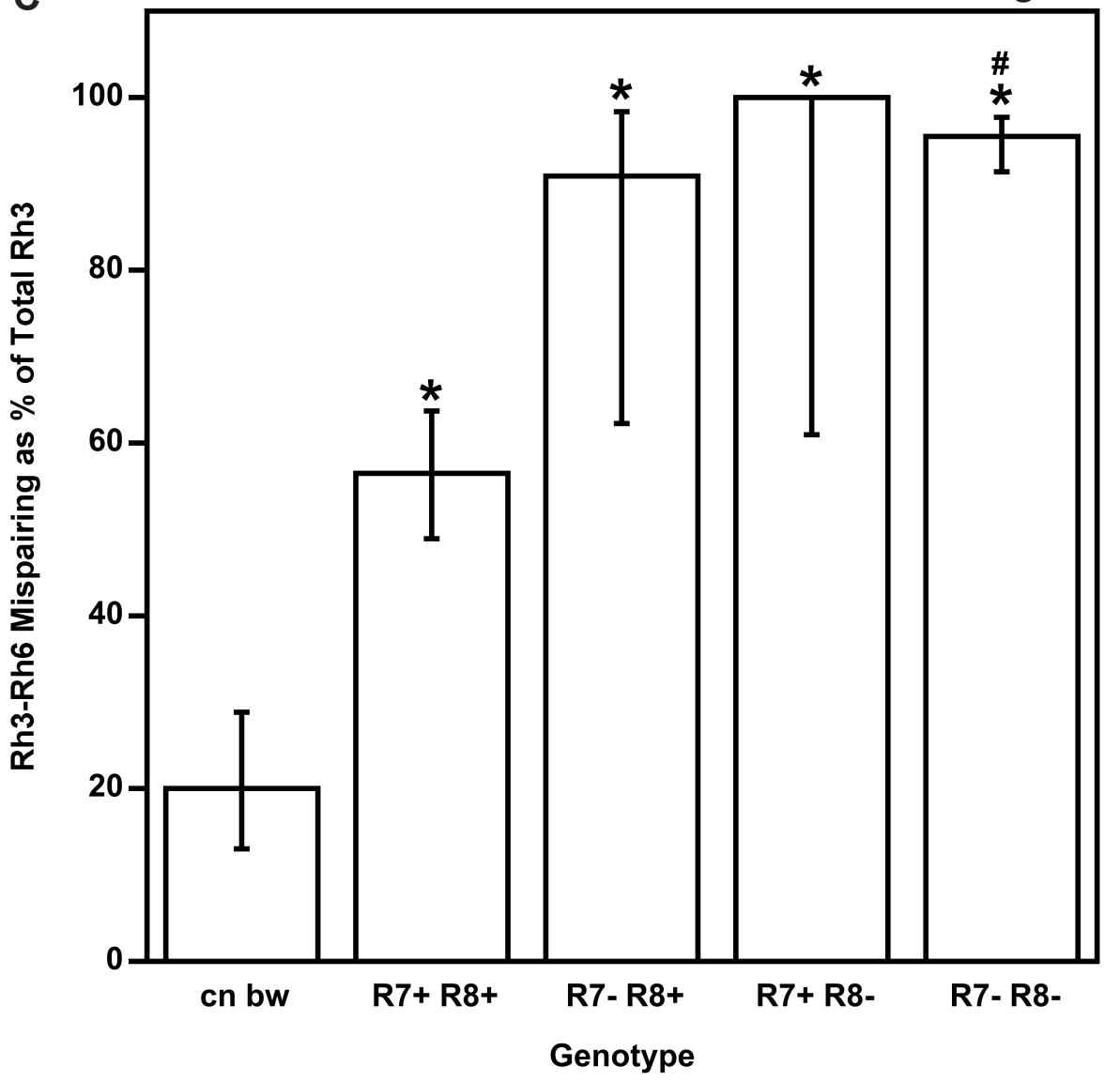


Fig 11
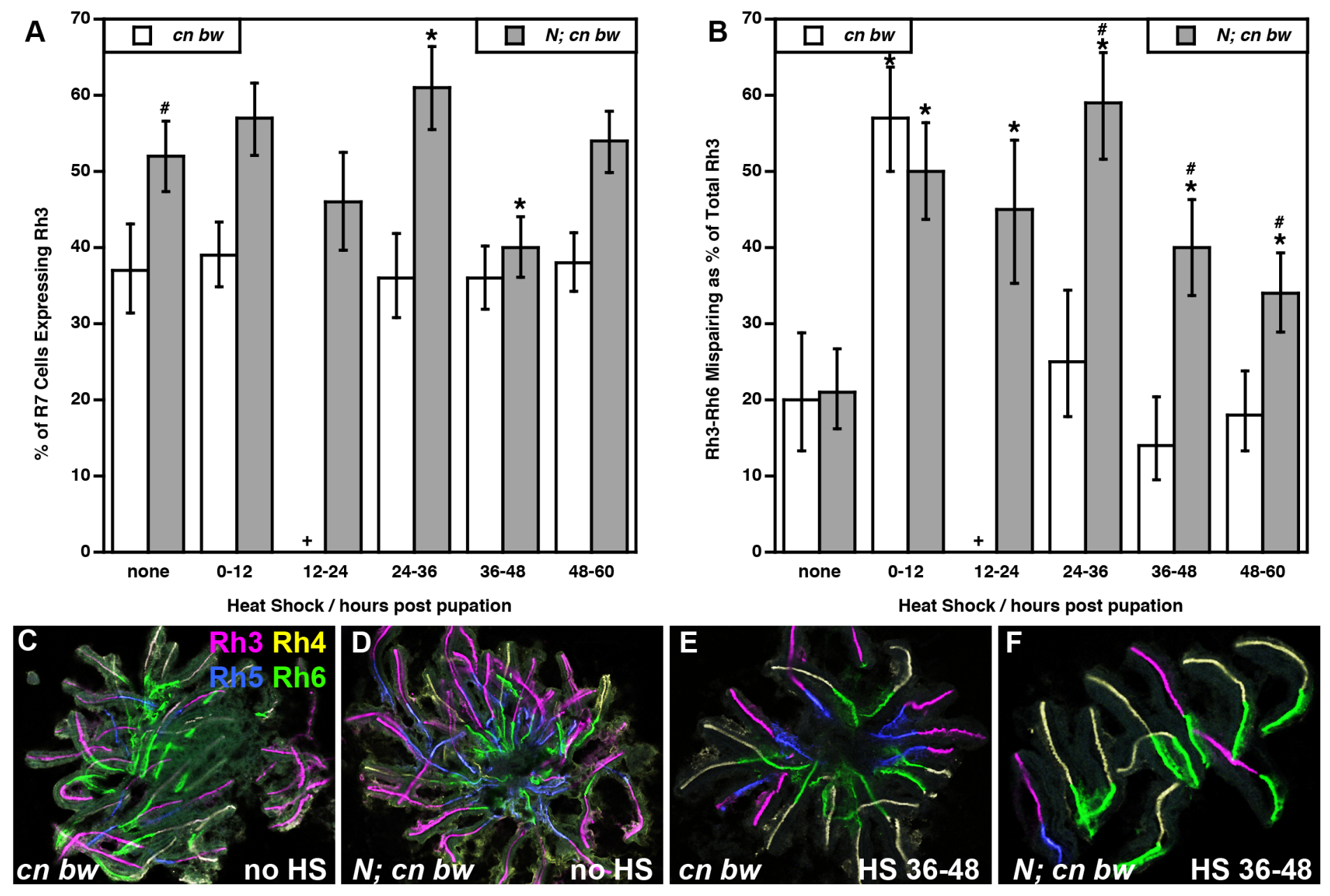